University of San Diego

Digital USD

2007-05-01

\title{
Factors that Motivate or Discourage Movement into School Leadership Positions and the Implications for Recruitment Policy and Practice
}

Ginger Lee Blackmon EdD

University of San Diego

Follow this and additional works at: https://digital.sandiego.edu/dissertations

Part of the Leadership Studies Commons

\section{Digital USD Citation}

Lee Blackmon, Ginger EdD, "Factors that Motivate or Discourage Movement into School Leadership Positions and the Implications for Recruitment Policy and Practice" (2007). Dissertations. 768.

https://digital.sandiego.edu/dissertations/768

This Dissertation: Open Access is brought to you for free and open access by the Theses and Dissertations at Digital USD. It has been accepted for inclusion in Dissertations by an authorized administrator of Digital USD. For more information, please contact digital@sandiego.edu. 


\title{
FACTORS THAT MOTIVATE OR DISCOURAGE MOVEMENT INTO SCHOOL LEADERSHIP POSITIONS AND THE IMPLICATIONS FOR RECRUITMENT POLICY AND PRACTICE
}

\author{
by \\ GINGER LEE BLACKMON \\ A dissertation submitted in partial fulfillment \\ of the requirements for the degree of \\ Doctor of Education \\ University of San Diego
}

May 2007

Dissertation Committee

Lea Hubbard, Ph.D

Paula A. Cordeiro, Ed.D

Kimiko Fukuda, Ed.D 
(C) Copyright by Ginger Lee Blackmon 2007

All Rights Reserved

Reproduced with permission of the copyright owner. Further reproduction prohibited without permission. 


\begin{abstract}
Public schools in the United States are facing one of the most extensive transformations in school leadership. Districts face the difficult challenge of recruiting and training school leaders who have the capacity to deal with the growing demands and responsibilities placed on school site administrators. Despite a surplus of people certified for administration, the changing demands of the principal's job precipitated by national reform efforts have left a shortage not only of qualified applicants, but also in the total number of applicants (qualified and unqualified) willing to carry the burden of the job. This study investigated the factors that influence principals' and teachers' decision to pursue school leadership and the impact those factors had on their recruitment. Qualitative research methods were used to address the following question: What structural, agentive, and cultural factors motivated and discouraged people from moving into positions of school leadership? Data were collected using an internet-based survey, and interviews were conducted with administrators and teachers in three districts. Analysis was conducted through cross-case method using domain analysis. This study suggests that an organization's structure and its culture are interrelated in the recruitment process. Administrators and teachers identified informal mentoring as the primary factor in their decision to pursue school leadership. However, a culture that fostered informal networks raised concerns that a different kind of "good old boys" network evolved, one not exclusive to white men. Formalizing a culture of mentoring is essential to enhancing districts' recruitment efforts. This study suggests that it is vital to recognize leadership traits among teachers through a formal institutionalized mentoring process, thereby creating a more effective recruitment path within districts and attracting more recruits.
\end{abstract}




\section{DEDICATION}

To my partner and best friend, Mary Logomasini for her patience, understanding and unconditional love throughout the process.

and

To my parents, Susie and Mike - for always believing in the dream. 


\section{ACKNOWLEDGEMENTS}

So many of our dreams at first seem

impossible, then they seem improbable;

and then, we summon the will, they

soon become inevitable. (Reeve, 2003)

I would like to thank all the people who gave me the power and determination to see this project to completion. It was a goal that remained ever present in my mind through many moments of accomplishment and trial, until one day it went from being a dream to a possibility, to a reality. Not a moment of this impossible dream was accomplishable without the support and love of many people, but most notable my partner, Mary Logomasini. I truly do not have enough words to express my love and gratitude for having you in my life.

Next, to my family and friends, you have taught me that life is about the people you love. I recognize the contribution each of you makes to my life and the fact that in your own ways you convinced me that this project was accomplishable. Susan, Sue and Heidi, I treasure your guidance and love which often feels more like family than friendship. Finally, to my twin sister Connie, you have always been my guiding light, your words and actions never allow me to forget the pride, promise, and potential of our lives.

Finally, to the individuals who helped me with the conceptualization and development of this research project. Thank you to my committee, Dr. Lea Hubbard, Dr. Paula A. Cordeiro and Dr. Kimiko Fukuda for your friendship, and encouragement. I am grateful to Dr. Cordeiro for the many conversations early in the project that helped me to determine the need to look at the critical issue of the recruitment of quality school leaders 
in this age of accountability. Thank you to Dr. Hubbard for guiding me throughout the actual study to produce a quality product of significance to the research community. And to Dr. Fukuda, our friendship that developed as a result of a formal principal mentoring program is priceless. You will never know the positive impact you have had on my development as a leader.

To the friends and mentors in my life whose words and actions continually guide me to be the best leader possible in my attempt to make the best decisions for children. Judy Brings, Heidi Eastcott, Stacy Spector, Wilma Kozai and Kari McVeigh - you are some of the finest educational leaders the profession has to offer.

I would like to extend my undying gratitude to Susie Gretler, Dr. Sue Gonda, and Dr. Susan Cayleff for the many hours spent reviewing the manuscript, sharing your insights and ideas, and moving this project forward. Thank you to Heidi Eastcott for getting hardcopies in the right hands by the established deadlines and taking care of paperwork that could only be done from San Diego. Finally, I am forever indebted to Dr. Gonda, for "taking the bullet" in the final weeks. I will never forget your help and support when I needed it most. 


\section{TABLE OF CONTENTS}

Acknowledgements ................................................................................................. vii

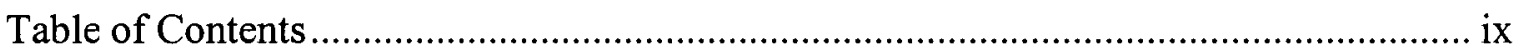

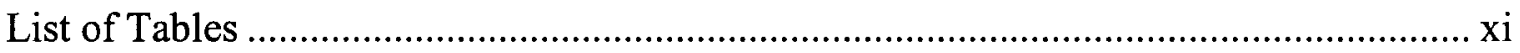

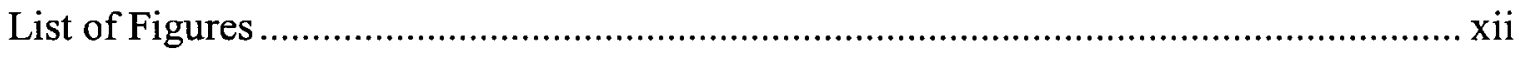

\section{CHAPTER}

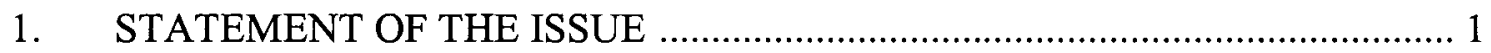

Introduction........................................................................................ 1

Statement of the Problem.......................................................................... 3

Significance of the Study ......................................................................... 4

Research Questions.................................................................................... 5

Overview of the Methodology .................................................................. 5

Delimitations and Limitations of the Study ............................................ 7

Definition of Key Terms ........................................................................ 8

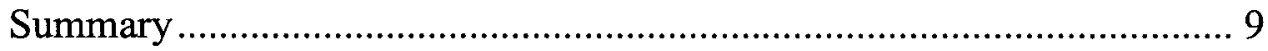

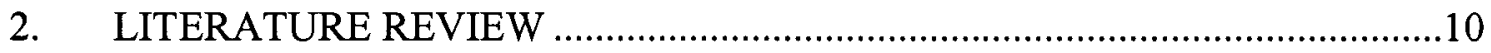

The Current Role of Principal..................................................................10

A Brief Historical Overview of the Principal's Shifting Role....................11

"Management Movements" That Reshaped the Role of Principal 13

Current Expectations Elaborated ...................................................14

The "New Principals:" Leadership Traits and Competencies......................17

Recruitment Challenges .......................................................................22

The Necessity for a New Language and New Methods..................24

The Relationship Between Recruitment and Selection...................26

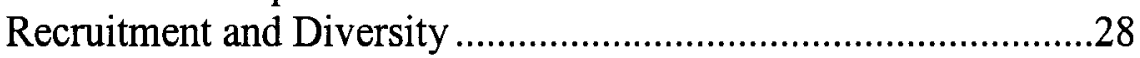

3. RESEARCH DESIGN AND METHOLODOGY ……......................................33

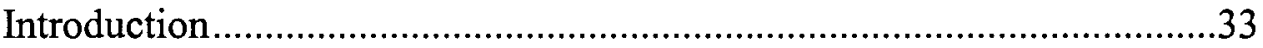

Research Questions ...............................................................................34

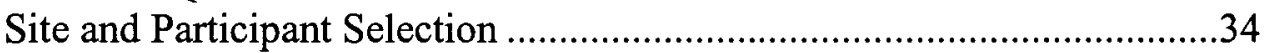

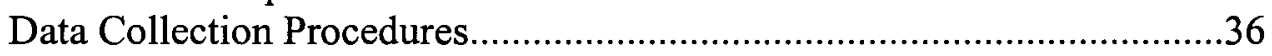

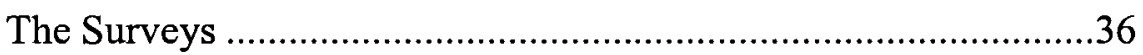

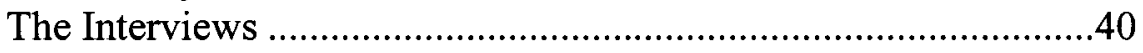

Researcher's Role and Assumptions.........................................................41

Data Analysis Methods ............................................................................43

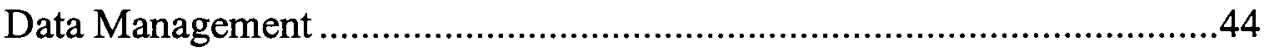

Delimitations and Limitations of the Study ...............................................45 


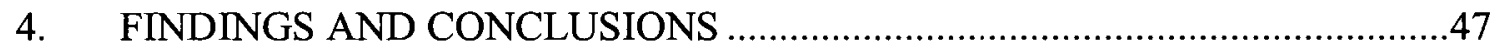

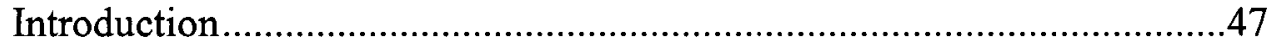

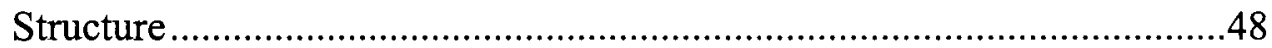

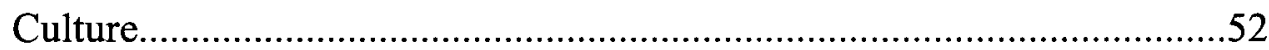

Informal Mentoring..........................................................55

Leadership Models and Skills for Effective Leadership...............58

Recruitment: Diversifying the Leadership Ranks.........................61

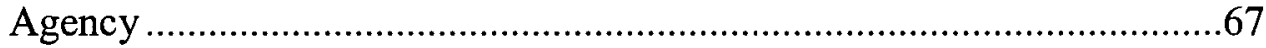

Factors Influencing Movement into Leadership .......................67

Personal Ambition .......................................................67

Impact of Leadership Models ......................................70

Family and Community Influence ...............................73

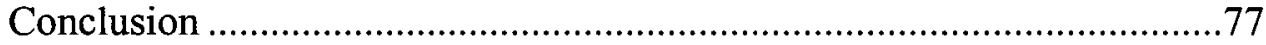

5. DISCUSSION, IMPLICATIONS AND RECOMMENTATIONS ......................80

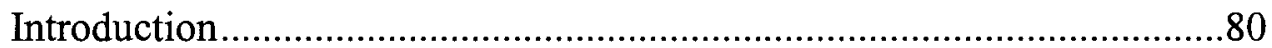

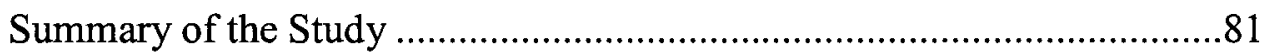

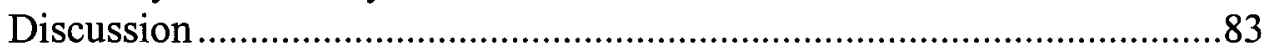

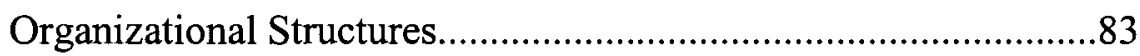

Cultural Influences: Mentoring.............................................86

Implications for Leaders and Policy Makers ........................................89

Interdependence of Culture and Structure ..................................89

Models of Leadership and Agency .......................................91

Recommendations for Further Study .................................................94

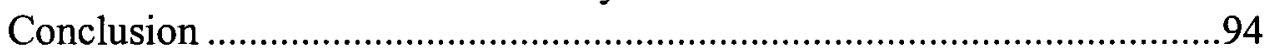

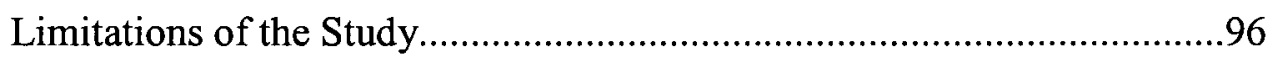

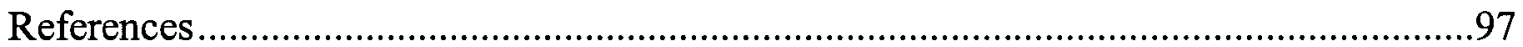

Appendix

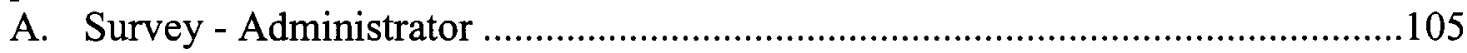

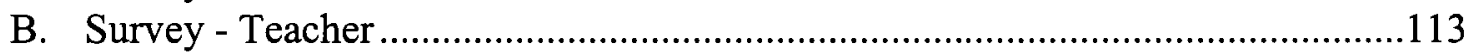

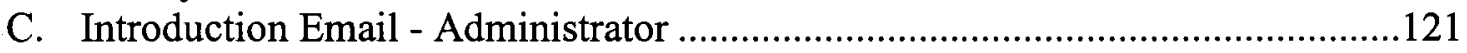

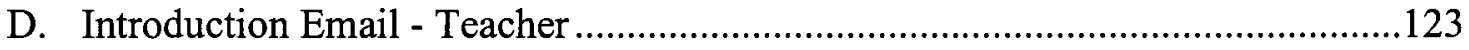




\section{LIST OF TABLES}

Table 1. Survey and interview participants by gender

p. 38 


\section{LIST OF FIGURES}

Figure 1. Race/ethnicity distribution of all survey respondents $\quad$ p. 38

Figure 2. Variety of school leadership positions held by survey respondents' $\quad$ p. 39 


\section{CHAPTER 1}

\section{STATEMENT OF THE ISSUE}

... a shrinking pool of candidates is stepping up to accept the ever-increasing demands and expectations of school leaders, and school communities across the country are facing the challenge of what is to comel (The Wallace Foundation, 2003, pg. 1)

\section{Introduction}

Public schools in the United States are facing one of the most extensive transformations in school leadership in more than a century. The Department of Labor (2006) estimates that forty percent of all principals are approaching retirement age and predicts that the job opportunities for school leaders should be excellent due to a large proportion of education administrators who are expected to retire over the next ten years (The Wallace Foundation, 2003; Department of Labor, 2006). Further predictions assert that school leadership positions will increase by twenty percent, 2003-2008 (The Wallace Foundation, 2003; Gates, 2003). Educational administrator vacancies are projected to exceed the average growth rate for all other occupations in the United States through 2012. Schools and districts across the country will have the unique opportunity and the significant challenge of recruiting, selecting and training an entirely new group of leaders.

This daunting task is occurring at a time of decreasing applications, and potential leaders have increased concerns about the difficulties of the job (Hertling, 1999; Levely, 1999; McCreight, 2001; Peterson \& Kelley, 2001). Ironically, studies show that in many

\footnotetext{
${ }^{1}$ Michelle A. Thompson, "Understanding the Job of a School Principal: A Study of Current Principal Practices and Principal Preparation" (report from the North Central Regional Educational Laboratory, November 2002), pg. 3.
} 
places throughout the country there are ample people certified for administrative positions, but their skills are often ill-suited for the task (The Wallace Foundation, 2003). Therefore, certification (gained through coursework and/or a standardized test) does not necessarily yield outstanding aspiring principals who can and will provide leadership in a rapidly changing field. This disparity in vacancies vs. qualified job applicants is critical: despite the numbers of talented educators, few pursue the job. Current leaders must focus on a solution for this disparity because newcomers will provide the foundation for schools' success or failure in the new millennium (Peterson \& Kelley, 2001).

For schools to attain society's expectations for student achievement, university preparation programs working with districts must also develop ways to recruit, select and train strong educational leaders into training programs. These newly recruited leaders must possess the desire and ability to facilitate the improvement of schools (Milstein, 1999).

This school leadership problem is exacerbated by the growing demands and responsibilities placed on school site administrators. Their job places them in the role of business managers, police officers and surrogate parents. Perhaps most significant is the pressure placed on principals due to the national sense of urgency to raise student achievement. It is difficult to recruit potential leaders who feel that they are ultimately responsible for the entire student body's success. This complex and demanding role of today's principal keeps many from pursuing the position (Whitaker, 2001; Gates, 2003; The Wallace Foundation, 2003). 


\section{Statement of the Problem}

Whitaker (2001) describes this growing problem in a study conducted by the Educational Research Service (ERS) in 1998 for the National Association of Elementary School Principals and the National Association of Secondary School Principals. The researchers sent surveys to 176 superintendents and 108 usable surveys were returned. Whitaker found that constant stress, (emotional, cognitive, and physical) and uncompetitive salaries keep many talented teachers from applying for administrative positions. Whitaker (2001) does not address the impact of the sweeping school reform efforts currently taking a firm hold in many districts and the impact on potential school leaders. However, Mary Lee Fitzgerald, Director of Education Programs for the WallaceReader's Digest Funds does consider the impact: "At the same time public school enrollments are growing, retirements are soaring. The principalship is a bull market, but nobody wants the job. Modest pay, long hours, uneven resources, problematic authority [and] increased expectations of the public make this job in a competitive market a nowinner for the top half of the class" (New Schools Venture Funds, 2003)

Current salary levels also drive away teachers who are qualified through years of experience. Long time teachers receive little, if any, pay increase for upward movement. In some cases they take a pay cut to become site administrators. Principals' salaries have not kept pace with the changing demands of the job caused by educational reform efforts aimed at raising student achievement. Together, then, low salaries, perceived job stress and changing policies and procedures have left a shortage in the total number of applicants (both qualified and unqualified) willing to bear the burden of the job. Because the demands of the job will not decrease, the applicant pool for school leaders needs to be 
expanded, the career options made more attractive and the process for selecting school leaders fine-tuned. Missing from much of the dialogue are specific recommendations for innovative methods of recruitment to expand the pool of qualified leader-candidates.

Under the circumstances, a need exists to: 1) examine the factors that influence a person's decision to pursue a school administrative position; 2) examine individual perceptions of the leadership skills and traits necessary for successful leadership; and, 3) assess the impact these factors have on recruitment practices. Answers to these questions will indicate how to improve recruitment policies and procedures and create a larger pool of qualified applicants.

\section{Significance of the Study}

America's schools are facing a leadership crisis. Retiring principals and changing demands of the job precipitated by school reform efforts have created a shortage of both qualified applicants and the total number of applicants willing to bear the burden of the job (Whitaker, 2001). Filling vacancies with skilled and knowledgeable leaders will be critical, since those selected will impact schools for a decade or more (Peterson \& Kelley, 2001). The national sense of urgency to raise student achievement presents a problem for recruiting potential leaders who ultimately are responsible for the success or failure of students at their sites (Whitaker, 2001). This study contributes to the current dialogue about factors that encourage or hinder individuals who are considering a move into leadership. This study adds a new level to the discourse by examining and recommending methods of recruitment that best motivate people to assume school leadership positions. Examining factors that are influencing teachers--and have already 
influenced current principals--to pursue administrative positions provides district personnel with valuable information. Conclusions from this study may ultimately result in improving recruitment policy and practice in the on-going effort to bring the best and the brightest into the critical role of school site leadership.

\section{Research Questions}

This study examines, in depth, the experiences of five current site administrators and three teachers to determine the structural, cultural and agency factors that influence their decisions to seek site leadership positions. The study utilized two research questions to improve recruitment of quality candidates for administrative positions.

1. What structural, cultural, and agentive factors motivate movement into positions of school leadership?

2) What structural, cultural, and agentive factors discourage movement into positions of school leadership?

\section{Overview of the Methodology}

This study is primarily qualitative in design. The research focused on two questions utilizing survey data and interviews of eight individuals (identified through the survey process). The small interview pool allowed for a richer, in-depth exploration of individual ideas about leadership traits and experiences and the thought processes of administrators and teachers as they considered, or advanced into site leadership. The survey provided demographic data and initial responses to the research questions; the 
interviews, however, served as the primary data collection method for answering the research questions.

Site and district level administrators and teachers from three San Diego County districts participated in this study. While the three districts were located in the same county, they were diverse in student population. District selection was based on their accessibility to the researcher, district size, grade level configuration ${ }^{2}$ and diversity of student population. Attention was placed on identifying administrators and teachers to interview from each district and from a range of grade level configurations.

Data collection was conducted through an on-line survey ${ }^{3}$ and face-to-face interviews. Introductory emails were sent to 219 administrators in all three districts in fall, 2005 with a link to the internet-based survey. Twenty-five administrators responded to the survey, and 11 volunteered to be interviewed. Access to teachers was gained through administrator responses to the on-line survey. Administrators were asked to provide names of teachers with leadership potential. Based on administrator survey responses, 25 teachers were sent an introductory email inviting their participation. Thirteen teachers completed the on-line survey, and 7 volunteered to be interviewed. Maximum variation was achieved by selecting participants based on: years of experience, gender, ethnic/racial backgrounds, and school levels within each district. Thus five (5) current site administrators and three (3) teachers were interviewed for this study. Variation among participants allowed for data comparison leading to the emergence of common themes. Additionally, variation allowed for generalization of study findings beyond the limited scope of this research study.

\footnotetext{
${ }^{2}$ Grade level configurations: Elementary School (K-5); Middle School (6-8); High School (9-12).

${ }^{3}$ Web-based service provider know as Survey Monkey (http://www.surveymonkey.com)
} 
Data Analysis was conducted on both survey responses and interview transcripts. A web-based service provider, Survey Monkey, collects responses and provides visual representations of the data as they are collected. Further, filtering options allowed for data manipulation to see relationships and filter out non-responses. HyperResearch, a computerized coding program, was used for data coding. Data collected from surveys and interviews were coded to discern categories of information and to identify factors that related to the research questions.

\section{Delimitations and Limitations of the Study}

My role as a principal in a local district at the time of the interviews presented a potential problem for this study. The politically charged nature of this district had the potential to impact individual participation and responses. The public perception of conflict between site administrators and teachers within my district may have prevented teachers from participating in the initial survey. Additionally, interview participants, particularly teachers, may have placed my role as a site principal over that of a researcher when responding to interview questions, thus skewing responses.

The study is limited in scope, as only three similarly-sized districts were examined, albeit with differing populations. The number and diversity of study participants were limited by the number of surveys sent out and returned. Proper functioning of recording devices presented a possible limitation of this study. One interview was not captured on audiotape; therefore quality note taking was critical during face-to-face interviews. Equipment failure during that interview required that handwritten notes be taken and the notes were later expanded with follow-up interviews in order to 
have maximum data for analysis. Finally, a professional service was used for transcribing the interviews. This resulted in the transcription of words or phases that were inaccurate because it was difficult to discern what was said. However, a review of the transcripts by interview participants helped to mitigate this problem.

\section{Definition of Key Terms}

Organizational Structure: "The plan for the systematic arrangement of work is the organization structure. An organization's structure is comprised of the functions, relationships, responsibilities, authorities, and communications of individuals within each department [of the organization]" (Sexton, 1970, p. 23).

Organizational Culture: The attitudes, experiences, beliefs and values of an organization comprise its organizational culture. Hill and Jones defined it as

The specific collection of values and norms that are shared by people and groups in an organization and that control the way they interact with each other and with stakeholders outside the organization. Organizational values are beliefs and ideas about what kinds of goals members of an organization should pursue and ideas about the appropriate kinds or standards of behavior organizational members should use to achieve these goals. From organizational values develop organizational norms, guidelines or expectations that prescribe appropriate kinds of behavior by employees in particular situations and control the behavior of organizational members towards one another (Hill \& Jones, 2001)

Agency: The capacity for human beings to make choices and to impose those choices on the world is called their agency. Agency entails the claim that humans do in fact make decisions and enact them on the world (Elder, 1998). 


\section{Summary}

Districts across the nation are becoming increasingly concerned that there is a shortage of qualified candidates to fill principal vacancies. This shortage is coinciding with massive educational reform efforts. A significant number of people are leaving school leadership positions, districts are experiencing difficulty in filling vacancies and new administrators often lack the skills necessary for successful school leadership.

This study seeks concrete solutions to this educational leadership crisis by determining the organizational structure, culture and agency factors that both motivate and hinder prospective leaders when school administration jobs become available. At present a gap exists in the literature identifying innovative recruitment methods that will address the growing concern of recruiting qualified candidates for school leadership. The research method employed for this study was intended to access the factors that influence current administrators' and teachers' decision-making processes. By understanding the multiple factors working independently and collectively to influence potential site leaders, policy makers, educational training programs and district hiring personnel can develop new, effective recruitment methods that bring the best and brightest to the selection process for principal vacancies. 


\section{CHAPTER 2 \\ REVIEW OF THE LITERATURE \\ Systems of schooling are over managed and under led.}

(Thomas Sergiovanni)

This literature review covers three areas: 1) the changing role of the principal overtime; 2) current leadership characteristics and competencies necessary for effective school leadership; and 3) the process of principal recruitment. The review begins with a focus on the evolution in the thinking about what principals should know and be able to do and the tasks principals perform in running effective schools.

The Current Role of Principals

Principals are held to a higher standard than was expected in the far and even recent past. The use of high stakes testing as an indicator of a principal's ability to successfully lead a school contributes to the challenge of recruiting school leaders willing to take on these growing demands and responsibilities.

Demands made of school systems due to societal changes are reflected in the transition of the principal's role from "head teacher" to "manager" to "instructional leader." As the role of principal has changed, so have the characteristics, traits, knowledge and skills needed by those in this position. The present day principal must know operational, instructional and pedagogical content. $\mathrm{He} /$ she must bring these skills to reform efforts that stress accountability for raising student achievement. Many principals are encouraged to look to successful business leaders as models. The hope is that they will learn how to trim bureaucratic functions within the organization or school, focus on 
measurable goals, manage through incentives and penalties and hold employees accountable for reaching desired goals (Cuban, 2001).

This multifaceted and demanding role is relatively new. In fact according to Anderson (1991) a principal's leadership ability is currently discussed as the most crucial element necessary for student success.

\section{A Brief Historical Overview of the Principal's Shifting Role}

It is believed that historically the prominent role of principal came about in the middle of the 19th century as populations in towns increased and one-room schoolhouses grew to include larger numbers of students (Kimbrough \& Burkett, 1990; Murphy, 1990a; Murphy \& Hallinger, 1992). Schools began to employ a variety of teachers. One room-school houses gave way to school buildings. This created the need for "head teachers" or "principal teachers" who could oversee the growing number of administrative duties.

The massive influx of immigrants, $1880-1920$, and the shift to mandatory school attendance created the need for a new educational system. The early $20^{\text {th }}$ century school that sorted students by age level necessitated that educators' have knowledge of childhood development and required professional preparation of teachers. It expanded the scope of the curriculum, and created the need for an ever-more-qualified principal (Spain, Drummond, \& Goodlad, 1956).

Particularly, separating children into a graded system brought with it educational changes that accelerated the demand for leadership (Spain, Drummond, \& Goodlad, 1956, p.29). Now the school site leader was required to: maintain and organize 
instructional materials, equipment, student and organizational records, and monitor student success. The introduction of hierarchical structure resulted in the creation of the elementary school teacher, higher standards for teachers through licensure and performance review and the need for overarching leadership through a principal.

This first type of principal was employed to see that rigid standards of discipline were enforced, that rules were meticulously observed, and that teachers adhered to predetermined teaching methods that defined teaching content (Spain, Drummond, \& Goodlad, 1956, p.31). Interestingly, the majority of these principals (55\%) were female between 1928-1978.

By the 1970s, principals' duties had expanded even further. Cultural perceptions of children that included a more individualistic conceptualization of the needs of children once again placed new demands on the principal. Barth argued that: "principals were now responsible for: children's safe passage to-and-from school...health education, sex education, moral education... [minimum achievement at each grade level]...the development of children with special needs, of the gifted, and those who are neither" (Barth, 1980, p. 4). In short, the principal had become a "provider of social services, food services, health care, recreation programs and transportation - - with a solid skills education worked in somehow" (Barth, 1980, p. 4).

This constantly shifting role was reflected in the rapid name changes assigned to the one in the leadership position: in 1958 the title "principal" was not used at all; by 1978 nearly $93 \%$ of the people in this position referred to themselves as principal (Pharis and Zakariya, 1979). 
The late 1970s marked another turning point: more focus was placed on managing a school site rather than leading the instructional program. The shift led to a predominance of male principals ( $82 \%$ compared with $45 \%$ in previous decades) as men were thought to be better able than women to manage an organization.

\section{"Management Movements" That Reshaped the Role of the Principal}

Four major management movements reshaped the principal's role. They were: scientific, human relations, organizational behavior and human resources. Each movement built upon the preceding movement in the development of the principal's role. In the early $20^{\text {th }}$ century, scientific management prevailed, modeled on industrial expansion (Owens, 1987; Callahan, 1962).

By the 1930's human relation theorists argued that school attend to "human variability" as a key component of the organization if excellence was to be achieved (Hersey \& Blanchard, 1982; Owens, 1987; Roethlisberger \& Dickson 1939). Principals were required to increase productivity through democratic decision-making that stressed interpersonal skills and interactions. Less emphasis was placed on instruction and more on boosting staff morale (Owen, 1987). The human relations ethos guided school leadership until after World War II.

By the 1950s organizational leadership theory viewed schools as social organizations (Getzels \& Guba, 1957). In order to succeed, principals were expected to learn and balance organizational structure, individual personalities and job behavior. This necessitated that principals have the ability to: develop an appropriate leadership style for one's environment and circumstances; use motivational techniques to raise morale and 
increase productivity; facilitate conflict resolution; exhibit good human relations skills; and foster school improvement (Walker, 1995).

The fourth model asserted that a human resources approach would lead to organizational success. This was triggered by the release of the "Coleman Report," (1966) which asserted that socioeconomic and racial background factors largely determined student achievement in schools (Coleman, Campbell, Hobson, McFarland, Mood, Weinfeld, \& York, 1966; Cuban, 2001). Soon thereafter A Nation At Risk (1983) pointed out that our educational system could be characterized by "the rising tide of mediocrity" (p.1) and principals needed to play a stronger leadership role in moving schools away from mediocrity.

Research in the 1980s added even more demands on the principal. (Smith \& Piele, 1989; Buell, 1992; Findley \& Findley, 1992; George \& Grebing, 1992) They were now expected to manage a school's culture. The 1990s saw the human resources theory of principal leadership as the primary guide to effective leadership. Principals were expected to possess five crucial leadership abilities: technical, human, educational, symbolic, and cultural (Segiovanni, 2001). When properly utilized, theorists argued, this interpersonal leadership approach yields successful motivational techniques and could lead to greater academic achievement.

\section{Current Expectations Elaborated}

At present, theorists argue that principals' leadership requires support, encouragement and growth opportunities among teachers, staff and students. This is implemented within a framework that values instructional leadership over school 
management as the defining point for student success (Greenfield, 1987; Ubben \& Hughes, 1987; Smith \& Andrews, 1989; Kimbrough \& Burkeet, 1990).

Research suggests that (ideally) a successful principal should spend his/her time on instructional improvement within the classroom, yet, in actuality the demands of the job require devoting the majority of his/her time to personnel, program development, and school management. Yet, an extensive study published by the National Association of Secondary Principals (1990) reported that most principals surveyed said they spent the bulk of their time managing student behavior rather than focused on the instructional needs of the school.

Contemporary explanations or descriptions of the principalship are primarily centered on the ability of individuals to lead instructional work at their sites. Petersen's (1987) research provides insight into the behavior of principals as instructional leaders which include: regular observation of teachers and providing feedback; monitoring student progress by reviewing test results with teachers; working with teachers to build a coordinated instructional program; promoting staff development by securing resources and finding opportunities for growth; communicating to teachers their responsibility for student achievement; and acting as instructional resources to teachers by regularly discussing matters of instruction (Deal, 1987; Greenfield, 1987; and Peterson, 1987).

The actual demands--to function as both manager and instructional leader--are, often difficult (if not impossible) to realize. Sweeney (1982) asserts that principals lack the time to partake in leadership roles as they are too busy "being all things to all people" (Sweeney, 1982, p. 204). Other researchers (Rallis and Highsmith, 1986; Weiss, 1992) concur and note that the expectations are ill-formed. 
We doubt that principals can succeed by trying to be all things to all people; they are more likely to wear themselves out. The skills of management that are needed to keep order are very different from the skills of leadership that often encourage planned chaos (Rallis and Highsmith, 1986, p. 301).

Other theorists choose not to highlight the impossibility of these competing dual functions. George and Grebing (1992) assert that one can both manage a site and lead as an instructor. Their list of traits necessary to accomplish this balance must straddle cultural sensitivity, shared decision making, team management, and future goals for excellence. The realities of the job site, however, inspired other researchers to suggest that delegation of work was necessary for successful outcomes (Richardson, 1987; Short \& Greet, 1997). Concurrent with these countless demands, an ideological shift urged principals to become "lead teachers." This was described by some as a transformational role (Leithwood, 1992).

Much of the research of the late 1980s and 1990s added another major responsibility to the already onerous role of principal. This research contends that the primary role of the principal is now to initiate and implement educational reforms. Richardson (1987) recognizes conflicts inherent in this changing expectation, but contends that the principal "continues to hold the key to school success as the gatekeeper of change" (p. 1). Scott Thomson (1992), the former Executive Secretary for the National Policy Board for Educational Administration agrees; “As demands grow on schools for improved quality and broader services, a new leader emerges. No longer managers of routines, school administrators need increasingly to take initiative. They must understand change as well as manage it" (p. vi). 
Weiss' (1992) inquiry as to whether that role of the principal "will survive as it exists now" (p. 202) was addressed in 1990, when the National Association of Elementary School Principals issued a report titled, Principals for 21st Century Schools. It concluded that even more would be expected of principals: leadership; instruction; decision-making; collaboration and better performing schools prime among them. In this model the tension between manager and educator is far from resolved, despite those who argue for its necessity. Principals often express the struggle with "being pulled in many directions simultaneously" (Leithwood, 2001, p.19), a conflict not faced by principals of the past (Colon, 1994; Short \& Greet, 1997; Elmore \& Fuhrman, 2001; and Calabrese, 2002). This is tellingly noticed by teachers who comprise the majority of potentially new entrants into school administration.

By the late 1990s the once-expected role of school leader expanded to require a principal to assume responsibilities as the leader of a learning community (DuFour \& Eaker, 1998; Senge, P. M., Cambron-McCabe, N., Lucas, T., Smith, B., Dutton, J., \& Kleiner, A. 2000; Sergiovanni, 1994, 2001). Principals no longer function to simply "run" a school, but rather to foster professional learning communities. Recruiting principals who possess the traits and competencies to be effective instructional leaders, and who can build and sustain this culture of learning, is the task ahead for school districts.

The "New Principal:" Leadership Traits and Competencies

To meet the needs for this "new" kind of principal, researchers have attempted to identify individuals who have the greatest potential to succeed. Striving for a common 
language (Young, Peterson, \& Short, 2001) researchers use observation, classification, identification, and evaluation to hypothesize what defines leadership from culture-toculture, and situationally (Gardner, 1980; Maxcy, 1981; and Yukl, 1989). Specific leadership traits have been noted by researchers as necessary for effective school leadership. While recognition of certain traits have shifted considerably since the 1950s, Yukl (1989) claims that innate traits could be the predictor of success.

By 1990 Bass and Stogdill's Handbook of Leadership, (1990) claims these innate traits are determination, persistence, self-confidence, and ego strength. Moreover they are crucial within all situational settings. The ability to perform tasks competently, relate well interpersonally and instill productive and effective values are key.

Given the increasingly complex role of the principal, considerable research has focused on the skills that individuals need to assume the position. To address the question of the leadership skills that lead to successful schools, Walker (1990) conducted a study to evaluate the skills of current exemplary principals by observing their behaviors in three national award-winning schools: one elementary, one middle, and one high school. The principal of each was shadowed for four weeks. Walker identified twelve key skills for effective principal leadership: problem analysis; judgment; organizational ability; and oral and written communication; decisiveness; leadership; sensitivity; stress tolerance; motivation; range of interests, and educational values. According to Gardner, (1980) to embody all of these attributes, intelligence and judgment-in-action must go hand-in-hand.

While these skills were found among current principals they varied in degree across principals because the ability to integrate all of these skills is not learned overnight. For first-year principals, one researcher suggested a crucial first step toward 
success is decisive decision-making (Bailey, 1992). To further complicate the skills perceived as necessary for the job, Snyder \& Drummond (1988) suggest that a principal must implement them with nuance, given the individual job's demands, the nature of the organizational environment, and one's own abilities.

One other tremendously important ability a principal must have is technological skills: the information age necessitates that leaders be skilled in an ever-widening variety of technical arenas. Technological skills (use of the internet, computer, etc.) are a requirement for bridging the gap between communities, countries, cultures, and lifestyles (Naisbitt, 1984).

Other research has pointed out that because principals are required to create collaborative communities, motivate others and implement a vision of excellence, an individual must be able to set a vision that focuses efforts towards a common purpose, raising student achievement. One researcher cautions that principals should not build visions that are too narrowly focused on their own vision lest they compromise collaborative efforts designed to work toward a shared vision. Instead, Fullan (1992) suggests that principals concentrate on building collaborative cultures. He maintains that this can be done by: valuing colleagues and fostering a team atmosphere that offers choice.

Management skills must be integrated alongside instructional leadership abilities. Instructional abilities draw on specific skills such as: knowing how to provide instructional resources and communicate and maintain a visible presence (Smith \& Andrews, 1989; Findley \& Findley, 1992). Principals must be visible in classrooms, as instructional leaders, working with teachers. They must communicate a vision for student 
success and provide the tangible and human resources necessary to accomplish this goal. Other researchers argue that principals must bring a flexible spontaneity to their instructional leadership. This is defined as the ability to problem solve (Bass, 1985) and a willingness to pursue change through risk-taking (Clough, 1988).

Above all else the key to actualizing instructional leadership is effective communication. Oral and written skills adaptable to different audiences are needed and principals must be able to express their vision and goals. Strong communication skills can accomplish much to enhance a principal's effectiveness. These include: convey a positive attitude, initiate and maintain organization, foster decision making, and motivate the faculty and staff to work hard (Clough, 1988).

The lack of clear communication between leaders and subordinates can hinder organizational members' ability to work together and increase the complexity of problems. A job well done (task competencies) will pale if embedded within poor interpersonal communications. Bass (1990) defines interpersonal competencies [beyond communication] as empathy, insight, heightened awareness, and the ability to give and receive feedback within a given context and the individuals who inhabit it. Many researchers agree that the necessity to be "people oriented," (Mazzarella \& Grundy, 1989; Smith \& Piele, 1989) means listening, as well as speaking.

Listening effectively can facilitate principals' getting to know the members of their learning communities. The best and most direct way to listen is by being visible, interacting and creating a positive school climate (Frase \& Melton, 1992). 
As the role of the principal evolved from manager to facilitator-leader, "effective leadership is no longer defined by getting the job done, but rather, the ability to get the job done through people" (Srivastva, 1986, pp. 71-72).

Demonstrably, in 1992, Kwalski, Reitzug, McDaniel, and Otto investigated teacher and principal perceptions of the skills required for principal effectiveness. They discovered that the technical skills which typically dominated the business world are not necessarily those needed in the field of educational leadership. Instead, interpersonal skills were typically selected as the most critical. This finding led the researchers to pose a radical question: should principals be selected based on their ability to get along with others rather than on previous administrative experiences that may have simply finetuned their technical skills? More common is the hypothesis put forward by Parks and Barrett (1994) who stress the importance of a combination of interpersonal, conceptual, and technical skills for future principals.

The successful integration of interpersonal, conceptual and technical skills is largely dependent on the personal values that define a person's leadership style. Personal values refer to the attitudes of leaders in relation to the organization and their subordinates. These values typically define who leaders are - their belief system and their leadership style. Bass (1990) defines personal values as what an individual believes and regards as right, important, and good. He supports his assertion with a study conducted by Peppers and Ryan (1986) which showed that when leaders willingly articulate a collective vision, it is because they are self-driven and value its importance. The ability to first "manage one's self" before managing others is widely acknowledged in the scholarship as a crucial aspect of instilling a shared value system (Lyman 1988; Buell, 
1992). Creating a true atmosphere of collective mission necessitates integrating other diverse values and internalizing a style of "treating people the way you want to be treated" (Marlowe, 1992, p. 30).

The countless and shifting expectations placed on principals requires a savvy recruitment process--a process that typically falls primarily to district superintendents. Since capable school leadership is crucial to the success of the educational system, then the principal recruitment process must be thorough, rigorous, and continuously reviewed, particularly in light of the research on skills needed for individuals to be successful principals. Since individuals recruited to this position must meet the changing role and growing demands of this culturally complex role, recruitment processes must keep pace. The often ignored problem, however, is that to date, little is known about how best to recruit potentially successful school administrators. The next section begins by discussing some current efforts that are being made and the challenges to them, the relationship between recruitment and selection, and finally a discussion of the recruitment challenges for people of color and women.

\section{Recruitment Challenges}

Given the current expectations placed on school principals, examination of recruitment issues is imperative to meet the need for potential school leaders. A study conducted in 2003 confirmed the urgency of this need:

Never before has the bar been set so high for America's public education system....Nowhere does that bar seem higher than in struggling urban schools where the achievement gap tends to be greatest. ...the nation's nearly 84,000 principals [are counted on] to lead the instructional improvement needed to meet tough new state and federal mandates. ...these increasingly challenging and often thankless jobs [are] less enticing... (The Wallace Foundation, 2003) 
Researchers agree on several key points that would help address this lack of potential leaders: the applicant pool for school leaders needs to be expanded, the career option must be made more attractive and the process for selecting school leaders must be fine-tuned (Anderson, 1991; Gates, 2003). Yet, what is missing from the dialogue is specific recommendations for innovative methods of recruitment.

Three regions have pioneered in innovations in their attempt to recruit and prepare individuals for the principalship. Leadership training program such as, the Philadelphia School District's Principals Academy, New Leaders for New Schools, and the Educational Leadership Development Academy at the University of San Diego, address the growing need to recruit and train quality school leaders. The concept behind these three programs is clear; principals must be excellent leaders, manage dramatic change, and provide a high quality education for all children, but specifically for the millions who underachieve.

But nearly all regions around the country lack innovative recruitment models. Further, training programs and districts fail to address several key points, relative to the job demands of school administration that discourage potential leaders. Prime among these are "inadequate training, insufficient salaries and a lack of general awareness of the positive aspects of school administration" (Young, Petersen, Short, 2001, p.8). Many qualified applicants prosper financially as classroom teachers with responsibility for only their students. Long time teachers receive little, if any pay increase for upward movement and in some cases even take a pay cut to become site administrators (Rodda, 2000; Whitaker, 2001). 
An additional factor emerges that shows just how underdeveloped the issue of effective recruitment practices is. In a large study conducted by The Educational Research Service (2000) for the National Association of Elementary School Principals and the National Association of Secondary School Principals, Whitaker (2001) concluded just that. They surveyed 176 superintendents and conducted follow-up interviews regarding professional preparation programs in their geographic areas and the number of qualified applicants. Superintendents mentioned the lack of qualified applicants, but failed to talk about what indicators qualified applicants should possess. One challenge is that superintendents often lack a common articulated set of skill descriptors that are necessary for the job and thus, the potential for successful recruitment efforts seems blunted from the start.

The Necessity for a New Language and New Methods

Another challenge to the recruitment process is that there is yet to exist a language that portrays the job positively. Teachers, as the potential applicant pool, see the stressors and competing demands faced by principals, but nowhere is this counteracted with a positive portrayal of the job. This effectively eliminates a pool of interested candidates and makes running ads no longer sufficient. It has become necessary to proactively promote the positive aspects of the job (Rodda, 2000; O'Laughlin, 2001; McCay, 2001). O'Laughlin (2001) argues that leaving recruitment to the personnel department does little to meet the current need to attract quality candidates. Instead aggressive steps are needed to increase the pool of candidates for administration. This need can most effectively be met through a comprehensive recruitment plan that has the commitment of all levels of the district. The plan must be a priority of the board, the superintendent, and current 
school administrators. There must be a systemic implementation in order to address the growing shortage.

O'Laughlin, one of the researchers who has done the most to suggest what these new methods should be, argues that a comprehensive approach to recruitment requires several key steps. These include school leadership that makes recruitment a priority and allocates resources to implement the plan; articulation of the rewards and positive aspects of the profession as selling points; innovative methods of contacting potential candidates; a "selling" of the district, including the benefits to the location; a streamlining and simplifying the application process; and devising a method, via technology to screen worldwide candidates. In Solutions and Strategies for IT Recruitment and Retention: A Manager's Guide Demers (2002) adds one more necessary tactic: there exists a need for districts to employ managers or "administrators" who will lead by example.

Several researchers also suggest the use of recent historically-learned lessons to inform recruitment strategies suggested for the future. They point out that presuming teachers are the sole applicant pool might be an antiquated notion. Understanding the hesitancy of potential administrators to leave established homes and realizing the unattractiveness of sacrificing time and money to pursue graduate work along with the relatively low regard in which educational administrative programs are held, significantly challenge the recruitment effort (Culbertson, Green \& Nelson, 1969; Farguhar \& Martin, 1971; Mitchell, 1982; Nickerson, 1982).

Unless new recruitment tactics are instituted rapidly, the number of temporary administrators will continue to skyrocket. This is the case in New York City where a 
study in 2000 showed schools experienced a turnover rate in administrators in excess of twenty-five percent over two-years.

\section{The Relationship Between Recruitment and Selection}

Recruitment and selection should be seen as one but then managed as two distinct tasks. In Competency Based Recruitment and Selection: A Practical Guide, a distinction between the terms recruitment and selection is drawn (Wood \& Payne, 1998).

Selection and recruitment are used interchangeably but we like to draw a distinction between the two. In our view, recruitment is a broad term used to communicate the notion of getting someone into the organization. As such, it covers everything from advertising to induction. ...Selection, for us, is focused at the point where a decision is made about who to recruit (p. 2).

Reed (1989) and Steller (1984) argue similarly that hiring policies should do both: recruit those who meet the criteria, then select those who are identified as able to acquire and develop necessary skills. Those identified need to be trained, evaluated and constantly reviewed. Researchers generally attach the topics of principal recruitment and selection to each other with little attention given to the important precursor to selection, that of recruitment. This is demonstrated by Reed (1989) who stresses the selection process, but gives little attention to recruitment processes. He suggests that when school boards and superintendents are establishing recruitment and selection policies, attention should first be given to the selection process. Reed argues that the selection process will drive recruitment practice, while emphasizing that both must be designed to recruit and select outstanding candidates from outside the district, as well as inside, in order to attract a diverse and desirable candidate pool that includes women and people of color. In some instances these two linked issues, recruitment and selection, are dichotomized. This weakens the overall effectiveness of both discussions (Baron, 1991; Whitaker, 2001). 
At times, the role of superintendents problematizes this dual process. Some want to control every phase of the principal recruitment (and selection) process, or they do not provide an accurate job description. Some undervalue recruiting (and selecting) local candidates. District demographic characteristics based on student enrollment significantly influences the degree to which superintendents prioritize recruitment (and selection) practices. These statistics color their selection decisions, as candidates who assume leadership may reflect the characteristic of the majority student population but may not possess the skills necessary to insure increased student achievement (Baron, 1991).

The researchers who identified these problems suggested that: school districts develop specific written policies and procedures for recruitment and selection; and districts should develop working relationships with other educational organizations (universities, professional organizations, etc.) to identify and select promising school site administrators. Two other researchers assert recruiting should be underway before a principal is needed. This can be done by building a pool of candidates (Goodland, 1984; Anderson, 1991).

In the early 1990 s researchers began articulating methods for building a pool of worthy candidates before the need arises. Anderson (1991) suggests grooming capable candidates long before vacancies are open by implementing in-district career ladders, and establishing district internships and training programs. He concurs with many researchers that recruitment processes need to include advertisements, announcements, letters to teachers and notices at placement bureaus. Announcements, he advises, should be posted as widely as possible and include distribution at universities, district offices, surrounding schools, professional bulletins and journals, professional meetings, and over the World 
Wide Web (Kahl, 1980; Goodlad, 1984; Fliegner, 1987; Wendel \& Breed, 1988; Reed, 1989; Anderson, 1991; Baron, 1991; Walker, 1995). Finally, Anderson suggests that districts detail specific information about the school for which a principal vacancy occurs. These should include special needs and characteristics of the school, staff needs, and information pertinent to the community and school's cultural background. Recruitment and Diversity

Doud (1989), in a nation-wide study, estimated that ninety percent of all principals were reported to be Caucasian alongside the rapidly increasing minority student population. He stresses the need to make every possible attempt to identify qualified minority candidates for the principalship and to facilitate their preparation. Similarly, another study the next year, Principals for $21^{\text {st }}$ Century Schools also highlighted the need to address the numbers of minority-background people recruited for school leadership positions (NAESP, 1990). Despite attention to this problem the statistics remain dismally unchanged in numbers of people of color who apply and are selected to school leadership.

There is no clear plan laid out on how to recruit qualified candidates of color (Jackson, 2001). Jackson suggests rethinking how individuals are recruited. She is less directive about how prospective leaders should be identified. Other researchers though argue that identifying potential candidates should be collaborative between colleges and universities, local school districts, and professional associations. Additionally, these systems should be structured in a way that provides equal access to individuals from all racial and ethnic groups. This process must begin early so that they are encouraged and 
supported in their professional development prior to assuming leadership positions (Doud, 1989; NAESP, 1990).

Marshall (1992) in The Assistant Principal: Leadership Choices and Challenges found informal recruitment methods have the greatest impact on the identification of potential assistant principals. "The administrator grapevine --- conversations, asides, gossip, phone calls, within and among districts --- serves a key information and referral function in selection" (Marshall, 1992, p. 34). Thus people of color must be seen as potential leaders who are included in these informal networks.

In terms of gender, Gates (2003) found that 43.7 percent of all public school administrators in 1999-2000 were women. Yet this study fails to differentiate amongst the levels of leadership positions women hold. It seems likely that women are more often utilized as vice principals, rather than principals (Gates, 2003).

Marshall (1992) insists that there must exist a feeling that women and people of color are valued within the system and not simply placed in administrative roles as tokens. School districts must embrace the belief that women and people of color are valuable contributors to the system and then deliver the message by encouraging them to apply for principal positions. As Marshall argued: "Without changes, [to the current system], schooling will suffer as competent women and minorities move away from education into careers with more equal access" (Marshall, 1992, p. 94). Marshall outlines strategies for increasing the ranks for women and minorities in school leadership positions. She suggests "paying women and minorities to speak to perspective teachers and serve as roles models, to focus scholarships and internships on women and minorities, to require school boards and administrators to address the barriers faced by 
women and minorities and finally to disseminate information about employee rights." She also advocates making available specific information about how to use media, grievance action, and class action lawsuits to get school districts to take action to equalize the access of women and ethnic minorities to administrative careers" (Marshall, 1992, p. 95).

Given the changing conditions, expectations and challenges faced by principals what has encouraged existing principals or those considering movement into the position. If we are to address the problem of recruiting quality candidates, we must be helped by understanding what motivated those already in these positions.

Knowing that people of color and women often have additional challenges when seeking career advancement, it is important to understand how these groups have overcome the obstacles. The present study is designed to expose the experiences of current administrators that motivated them to seek site leadership. Additionally, discovering the factors that motivate or discourage teachers to assume leadership positions will help us develop recruitment practices that will increase the qualified candidate pool.

We need to know what polices and practices, both formal and informal, must be organized that will address all of these important recruitment issues. This study adds to that body of knowledge by revealing the role of mentorship in encouraging teachers with leadership potential. Mentoring is a significant line of research but, one that has not yet been adequately studied. We know little about the role of mentorship and its relationship to the principal recruitment process. Some research indicates that in general, mentorship is successful in attracting teachers to the teaching profession, supporting new teachers in 
developing their teaching effectiveness, supporting women and people of color into and through the ranks in business, and helping students become academically oriented (Office of Research, 1993; David, 2000; Holloway, 2001).

In conclusion, all the research discussed here has highlighted the present and crucial need for excellent caliber school administrators. But persistent obstacles to the recruitment of these highly talented individuals continue to exist. The persistent image in the minds of educators and the general public that the principal is “...the over-worked, underpaid principal-bureaucrat tangled in a web of administrivia, unionized teachers, uninvolved parents, and disinterested students" works against recruitment efforts (Fenwick \& Pierce, 2001, p. 25).

Research continues to demonstrate the significant changes to the role of the school principal, a role more demanding and challenging than ever before. Unfortunately, the research illustrates how recruitment procedures have not evolved over time to identify and hire effective school leaders in light of the changing role.

The Fenwick study (2001) concludes with the rhetorical question: "Who would want the job?" The answer lies in developing and putting into place programs that look beyond (or more closely at) the current pool of certified teachers. It is clear that the old ways of recruitment will not yield the innovations needed for future, national, educational excellence. Scholarship such as this study is needed to address mentorship and the other formal and informal processes that affected decisions of those already in the principalship. This research identifies the factors that influence a person's decision to seek a principalship. Discovering these factors provides insight into new and innovative recruitment methods aimed at increasing the pool of qualified candidates. In the next 
chapter I outline my methodology and then discuss my findings from the perspective of the structure, cultural and agentive factors that impact a person's decision move into site leadership. 


\section{CHAPTER 3}

\section{RESEARCH DESIGN AND METHODOLOGY}

The phenomenologist is committed to understanding social phenomena from the actor's own perspective. He or she examines how the world is experienced. The important reality is what people perceive it to be (Taylor \& Bogdan, 1984, p. 1-2).

\section{Introduction}

A significant number of all principals in the United States will be retiring within the next ten years (Gates, 2003; The Wallace Foundation, 2003; Department of Labor, 2006). Given the problem of recruiting experienced candidates into school leadership positions, this study examines factors that both motivate individuals toward, and discourage them from, school leadership.

This study is primarily qualitative in design. Patton (1990) asserted that when framing research it is necessary to "determine the extent to which it is desirable to study one or a few questions in great depth or to study many questions but in less depth" (p. 162). To obtain a richer analysis of administrators' and teachers' leadership traits, experiences, and thought processes, I have focused on only two questions utilizing interviews of eight individuals: five administrators and three teachers. The purpose of the interviews was to explore their thought processes as they considered, or advanced in, school leadership careers. The decision to interview follows the logic of Patton (1990) that the "power of purposeful sampling lies in selecting information-rich cases for study in depth" ( $p$ 169). The interviews served as the primary data collection method for answering the research questions. 
In addition to interviews, data from a survey of twenty administrators and thirteen teachers provides insight into their perceptions of personal and professional skill traits needed for effective school leadership. Survey and interview data from both principals and teachers allowed for compilation of demographic data and comparison of their insights about leadership: insights from those currently in administrative positions and from those who may desire to move into a school leadership role.

\section{Research Questions}

This study examined, in depth, the experiences of five current site administrators and three teachers to determine the structural, cultural and agency factors that influence their decisions to seek site leadership positions. This study utilized two research questions to identify these factors in an attempt to assist in the effort to recruit quality candidates to pursue administrative positions.

1. What structural, cultural, and agentive factors motivate movement into positions of school leadership?

2) What structural, cultural, and agentive factors discourage movement into positions of school leadership?

Site and Participant Selection

Principals, vice-principals, district level administrators and teachers from three San Diego County districts provided "information rich cases" for this study - those that have the potential for providing maximum information about the research questions. San Diego County is located in Southern California and borders Mexico. San Diego County Schools 
is comprised of forty-two individual school districts. Purposeful random sampling was used to select districts and participants (Patton, 1990). Participants were selected from three districts located in the same geographic area but diverse in student population. School district selection was based on accessibility to this researcher, a large district population and diverse student enrollment. The larger size of school districts allowed for a larger pool of candidates to pull from and the potential for more variation in sample selection. Additionally, the diverse student populations [age, race/ethnicity, languages] provided an assortment of perspectives from research participants. Selected schools encompassed suburban, urban and rural areas of the county. A larger urban district within the county was among the original three districts identified for this study. The difficulty in navigating the approval process to conduct the study within the large urban district led to the selection of a different district that was more comparable in size, but more diverse in student population [race/ethnicity, social economic level] from the other two school districts. Each administrator and teacher interviewed for this study works in one of the three districts. Another criterion for selecting participants was representation or experience from each of the three grade levels: elementary, middle and high school sites.

District $\mathrm{A}$ is in the southern portion of the county closest to the Mexican border. One in two students speak a language other than English at home and thirty-three different languages can be identified in the district. The district serves approximately 39,000 students in grades seven through twelve. District B is a south-central urban district that boasts the second largest population in the county. It serves a kindergarten through grade six student population of approximately 26,000 . District $C$, in the northern part of the county, is a kindergarten through twelfth grade district serving approximately 
33,000 students. It encompasses both suburban and rural areas and has a larger white population than the other two districts.

\section{Data Collection Procedures}

The Surveys

To target individuals for the survey, an introductory email was sent in fall, 2005, to district administrators in the three districts. The email was sent through a central office contact person and contained a link to an internet-based survey. The survey served to collect demographic data and to identify traits and characteristics important to the respondents for successful leadership. The survey was also a starting point for gathering data on factors that influence a person's decision to pursue school administration (Appendix C). During the survey design, two pilot studies were conducted to obtain feedback and refine the survey questions. Pilot study participants consisted of three current administrators and three teachers with whom I have a congenial professional relationship and who were willing to provide critical feedback. In the survey, administrators were asked to provide names of teachers $\mathrm{s} /$ he believed had the potential to be an effective school site leader. Those teachers were then sent a similar survey-asking the same demographic data such as gender, age, race/ethnicity, years of experience, education level including the possession of an administrative credential, current position, past experience and perceptions on district recruitment practices that work to diversify the leadership ranks. The surveys differed in the questions used to gather preliminary data that focused on the research questions (Appendices A \& B). 
Initial data collection, then, was conducted through this semi-open-ended survey that elicited demographic data as well as responses to the research questions. The on-line survey responses were submitted anonymously. However, surveys to principals and teachers gave participants the opportunity to provide name and contact information if they agreed to be considered for further participation in the study.

A total of 219 surveys were sent to district administrators in three districts. One hundred and forty-seven surveys were distributed in District A; District B distributed forty surveys; and thirty-two surveys were emailed to administrators in District C. In District A the administrator survey was distributed to every administrator within the district, at both the site and district level. Survey distribution in District B and District C was limited to site principals. Twenty administrators $(9 \%)$ across the three districts completed the survey and eleven site administrators (5\%) volunteered to be participants in the interviews.

In addition, site administrators were asked in the survey to provide the names and email addresses of teachers they believed possessed the qualities for successful school leadership. Administrators identified twenty-five teachers to contact through the on-line survey. Thirteen teachers (52\%) responded to an email inviting their participation in the study by completing the survey. Seven of the thirteen teachers (28\%) volunteered to be interviewed. Each teacher interviewed for this study works in one of the three districts. 
Table 1 Survey and interview participants by gender

\begin{tabular}{|c|c|c|c|c|c|c|c|}
\cline { 2 - 8 } \multicolumn{1}{c|}{} & \multicolumn{9}{c}{ Teachers } & \multicolumn{1}{c|}{ Administrators } & \multicolumn{1}{c|}{ Teacher/Administrator } & Total \\
\cline { 2 - 9 } \multicolumn{1}{c|}{} & Female & Male & Female & Male & Female & Male & \\
\hline Surveyed & 6 & 7 & 8 & 10 & 14 & 17 & $31^{*}$ \\
\hline Interviewed & 2 & 1 & 3 & 3 & 5 & 4 & 9 \\
\hline Note: *Thirty (33) total survey respondents - Two (2) administrators declined to answer gender question. \\
\hline
\end{tabular}

Survey data were collected to understand administrators' and teachers' gender, age, race/ethnicity, training, educational level, and the kinds of leadership positions held before assuming a site leadership position. Respondents were all over the age of 31 with the largest concentrations being 41 and 45 years and 51-55 years of age. Fifty-five percent of the respondents were male and the majority identified as white.

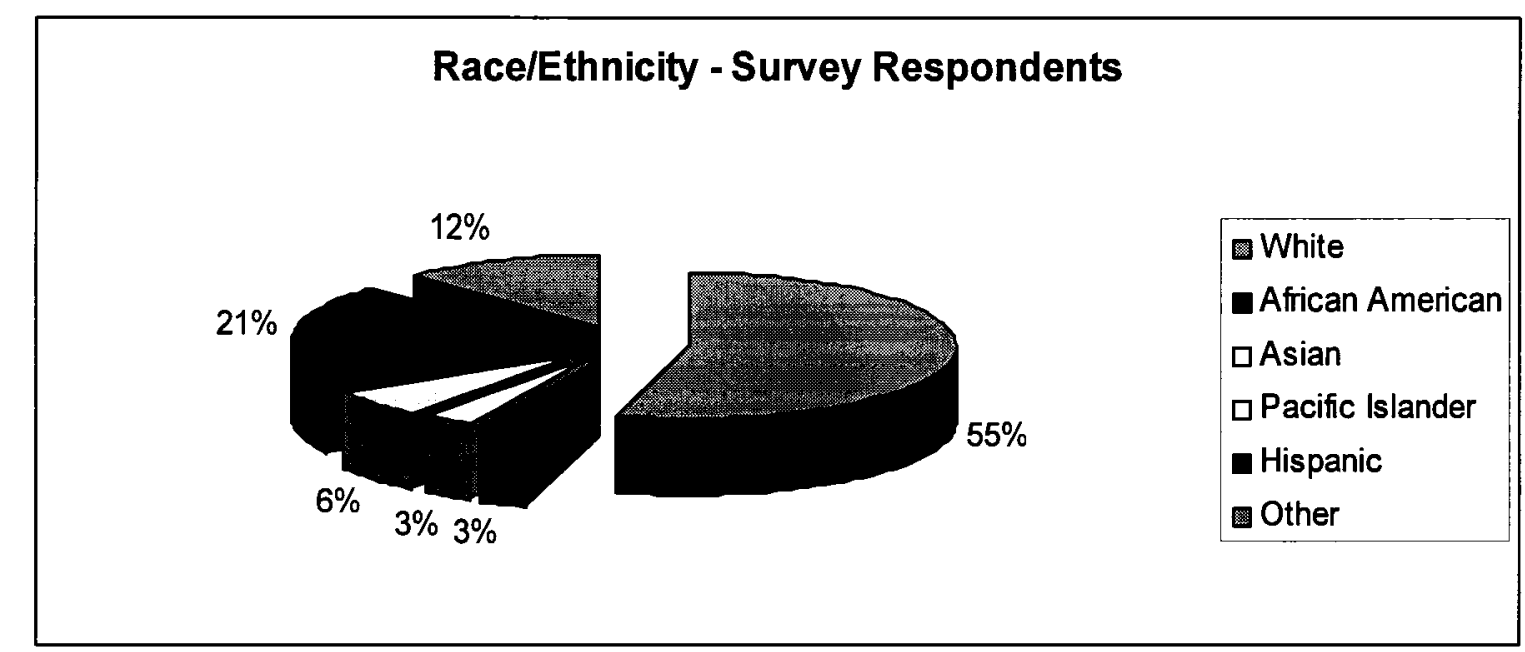

Figure 1. Race/ethnicity distribution of all survey respondents

The years of educational experience spanned 4 to 37 years with an average of 21.4 years of service. All administrators who responded to the survey hold Master's degrees, yet only thirteen (65\%) hold Master's degrees in Education. Four respondents (20\%) hold Doctorate degrees. All current administrators who responded to the survey held leadership positions within their schools before moving into administration. 
Seventy-nine percent of all respondents presided over their content department or grade level team during their career and all served on shared-decision making committees.

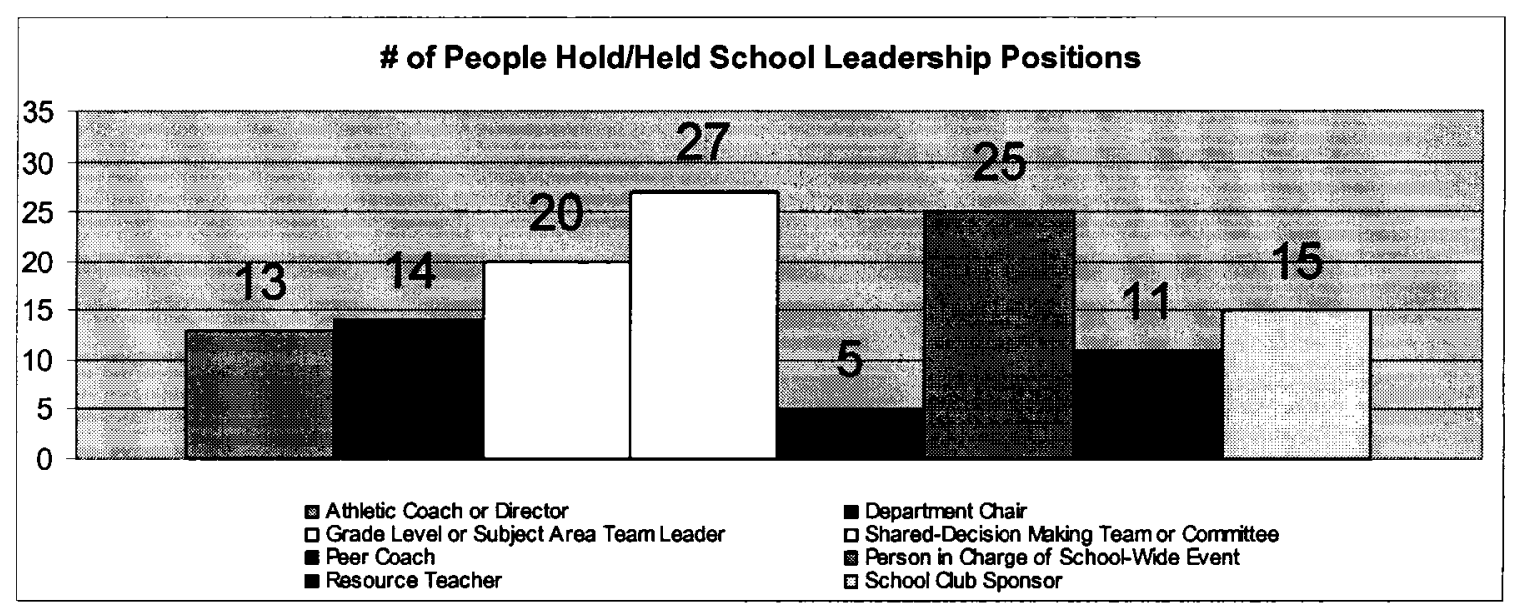

Figure 2. Variety of school leadership positions held by survey respondents

Forty percent of current site administrators had taught ten or more years, while twenty-five percent spent less than one year in a combined classroom teacher/resource teacher position. Twenty-five percent worked at the site level as full-time resource teachers compared to fifteen percent who experienced the functioning of a larger organization as district resource teachers. Four administrators gained instructional leadership experience as Peer Coaches ${ }^{4}$. Fifty percent of the current administrators who completed the survey spent 2-4 years as a vice principal before ascending to the top leadership role at a school site. Four principals moved directly from classroom teacher or resource teacher to their current positions.

Survey questions further served to gather data to address the research questions. Data were gathered on the traits and characteristics that administrators and teachers believe good leaders model. Knowing the traits of effective leadership helps to

\footnotetext{
${ }^{4}$ Peer Coaches are teachers who work with classroom teachers to improve teacher practice through a nonevaluative coaching model.
} 
understand the relationship between the models presented and the organizational culture that mentors potential leaders.

Ninety-five percent of current administrators who completed the on-line survey and all interview participants identified twenty-three descriptors that embody the characteristics of an effective school leader. Characteristics such as attitude, ability to see the big picture while attending to the details, being a change agent, effective time management, ability to embrace differences in people, ability to act as a student advocate, be a learner, a listener, have a sense of humor and a strong work ethic were descriptors used solely by site administrators. The ability to foster relationships was the single trait identified by teachers for successful leadership.

\section{The Interviews}

Patton (1990) describes the variety of questions for interviewing and different approaches to asking questions. Among these methods are open-ended questions and an interview-guide approach. An open-ended interview process in November and December, 2005 allowed participants to direct the discussion through their own words and thoughts. Using an interview-guide approach allowed the discussion to remain conversational and flexible. It also ensured that consistent material was covered by each participant (Patton, 1990; Bogdan \& Biklen, 1998).

Five administrators' and three teachers' interviews were taped and transcribed verbatim. The document was then sent to the participant for review to ensure that their thoughts and ideas were accurately represented. The participants were asked to review the transcript for accuracy and to clarify responses as needed. Follow-up interviews through email exchanges were conducted in January - March 2005. The questions 
focused on clarifying responses from the initial interviews. Participants were not all asked the same questions, but were asked questions specific to their original answers. Initial interviews were approximately one hour in length and conducted face-toface at a place determined by the participant. Given my role as a principal in a local district, face-to-face interviews allowed for the establishment of trust and rapport with the study participants. Note taking was conducted for all interviews in case the audiotape player technically malfunctioned, which it did on one occasion and the interview was expanded upon from these notes immediately following the interview.

Maximum variation was achieved by selecting interview participants based on: years of experience, gender, ethnic/racial backgrounds, and school levels within each district. Variation among participants allowed for data comparison thus helping to identify common themes. Moreover, variation allowed for generalization of study findings beyond the limited scope of this research study.

\section{Researcher's Role and Assumptions}

As a site principal I was interested in the factors that motivate or discourage a person from seeking school leadership. This research offered a way to explore the factors that influenced career decisions of current administrators. Additionally this research helped to gain insight from teachers about the structural, cultural and agentive factors that support or hinder career movement. It is important to study the perspectives of individuals whom current school leaders believe have the traits to successfully lead our schools. 
I was interested in knowing what aspects of school leadership discourage teacher leaders from seeking career advancement and their ability to have a broader impact on student achievement. Moreover, I wanted to know how the organization works to foster the awareness and understanding of teacher leaders about the roles and responsibilities of school leadership. A limitation in literature is the lack of knowledge about how teachers view the principals' role. Also missing are recruitment techniques that will cultivate a positive and accurate perception of site leadership and increase the pool of qualified candidates to fill anticipated vacancies.

This research design falls into the category of phenomenological inquiry (Patton, 1990) that aims to discover what people experience in context-specific settings and how they interpret the world. Patton asserts that a misconception in the methodology of phenomenological research is the belief that the only way "for us to really know what another person experiences is to experience it for ourselves" (Patton, 1990, p. 70). He addresses this misconception by arguing that a phenomenological perspective can be:

...either or both (1) a focus on what people experience and how they interpret the work (in which case one can use interviews without actually experiencing the phenomenon oneself) or (2) a methodological mandate to actually experience the phenomenon being investigated (in which case participant observation would be necessary) (Patton, 1990, p. 70).

My experience and role as a school site administrator afforded me the ability to interpret participants' experiences from shared experiences. However, I felt personally answerable for the validity of the respondents' experiences as unique in their own right, while working to find the commonality in the human experiences of all participants. 


\section{Data Analysis Methods}

Survey Monkey, a web-based service provider, was used to collect the survey data and helped narrow the interview pool in a way that maximized variation, (district, gender, race and ethnicity, and experience), from principals and teachers. In addition to survey design functions, Survey Monkey collects responses and creates graphs and charts as data are collected. Individual responses were viewed separately from other participants. Additionally, filtering options allowed further manipulation of responses to see relationships and to filter out non-responses. Demographic data collected from surveys was used to select interview participants. Using the graphing/chart capabilities of Survey Monkey, participants were selected to achieve maximum variation across districts. Further, survey responses from interview participants were used in the data analysis relative to administrators' and teachers' perceptions about the traits and characteristics of effective leaders and the factors that influence their decision to pursue school leadership. HyperResearch, a computerized coding program, was used for coding data from survey responses and from each interview to discern categories of information and to identify factors that related to the questions that guided this study. Finding central themes through "domain analysis"5 was the data analysis method employed for this study. Data analysis began simultaneously with data collection. As categories, themes and patterns emerged from the data, individuals with common themes were grouped to facilitate the comparative process. Comparison within like groups such as current administrators or teachers was analyzed first. This comparison allowed for commonality and differences in motivating factors to surface within a common group: those who already are in leadership

\footnotetext{
${ }^{5}$ Domain analysis: a method of analyzing for the cultural symbols which are included in larger categories see Spradley (1979).
} 
positions, and those who are thinking of seeking site leadership. After individual comparisons within similar groups were conducted, cross-case analysis was done to discern commonalities and differences in themes between the administrators and teachers (Spradley, 1979; Patton, 1990; Glesne, 1999).

\section{Data Management}

Survey data were collected using a web-based service. Throughout this study the web-based service stored survey data on-line. In May 2007 all survey data was printed and stored with interview transcripts and the web-based service, through Survey Monkey, was terminated. A separate electronic and hard copy file about each participant that contained the transcripts, field notes, coding, and survey responses.

Participants were not identified by name or location in the computer files. The exception is the survey where participants volunteered name, location and contact information. These data were deleted when service with Survey Monkey was discontinued in May 2007. Care was taken to remove identifying information from printed survey responses. Pseudonyms were used in all written reports and computer files. Any additional identifiers were removed during coding to ensure that none of the data in the final document was traceable to participant's identity. Data files were stored on a password protected computer system.

A transcriber was used to transcribe the audiotapes of interviews. After a review and comparison of transcriptions and audiotapes to correct noticeable errors and gaps, documents were sent to the appropriate interview participant for review. Upon return of the corrected documents from participants each transcript was reviewed for specific 
references to the participant and replaced with the assigned pseudonym. Finally, email correspondences provided the only information that an administrator or teacher participated in the study and these along with survey responses, audiotapes, transcripts, and archival computer files were stored in a locked filing cabinet.

\section{Delimitations and Limitations of the Study}

My role as a principal in a local district at the time of the interviews presented a potential problem for this study. The politically charged nature of this district had the potential to impact individual participation and responses. The public perception of conflict between site administrators and teachers within my district may have prevented teachers from participating in the initial survey. Additionally, interview participants, particularly teachers, may have placed my role as a site principal over that of a researcher when responding to interview questions, thus skewing responses.

The study is limited in scope, as only three similarly-sized districts were examined, albeit with differing populations. The number and diversity of study participants were limited by the number of surveys sent out and returned. Proper functioning of recording devices presented a possible limitation of this study. One interview was not captured on audiotape; therefore quality note taking was critical during face-to-face interviews. Equipment failure during that interview required that handwritten notes be taken and the notes were later expanded with follow-up interviews in order to have maximum data for analysis. Finally, a professional service was used for transcribing the interviews. This resulted in the transcription of words or phases that were inaccurate 
because it was difficult to discern what was said. However, a review of the transcripts by interview participants helped to mitigate this problem. 


\section{CHAPTER 4}

\section{FINDINGS AND CONCLUSIONS}

I used to tell my husband that, if he could make me "understand" something, it would be clear to all the other people in the country. (Eleanor Roosevelt)

\section{Introduction}

This chapter presents an analysis of the data from interviews with five current school administrators and three teachers identified by their principals as possessing leadership skills necessary for school site leadership. In addition, data from thirty-three web-based surveys are used to gather demographics and to enrich the analysis of administrators' and teachers' perception of traits and characteristics necessary for successful leadership. (Figure 3) The data are framed by three factors that affect a person's decision to pursue administrative positions: organizational structure, organizational culture, and agency. Framing the analysis around these three factors helped in understanding the interactions and mechanisms that move a person to action. This analysis includes the perceptions of these factors by current school administrators and teachers who are considering whether to pursue an administrative position. I analyzed their perceptions of: good leadership traits, why and how people are recruited for site leadership and why a person would choose to move out of the classroom and into school administration. Analyzing the survey data from twenty administrators and thirteen teachers and comparing the interviews from five administrators and three teachers I determined factors that influence an individual to seek school leadership. Understanding the factors that influence the decisions of administrators and teachers must guide new recruitment methods and bring quality leaders to the selection process. 


\section{Structure}

Structural factors encourage or constrain decisions of those who ascend into leadership positions. Structurally, the policies and procedures that guide the district recruitment process had a significant impact on who was hired to lead schools.

Two out of five administrators discovered job openings through the traditional formal recruitment practices of advertisements and job fairs. However, beyond these, all five administrators were unable to elaborate on any other formal structures districts may employ to recruit qualified candidates for school leadership.

In fact, three administrators had little or no knowledge of the recruitment practices that led to their own selection. Yet, administrators did acknowledge that the district must have practices and policies pertaining to recruitment. As Ina, a principal with twelve years of experience at three different schools, noted "principal vacancies get filled, so the district must be doing something." However, she shared that she notices very little recruitment in the district, concluding that if it is happening through a formal structure, it must be happening externally. Recruitment efforts outside of the district keeps potential candidates in the district "in the dark" about opportunities, placing them at a disadvantage.

On the other hand, Giada, an administrator from the diverse south-central district, spoke of her district's training through a series of "New Administrator Workshops," which is open to those who are thinking about becoming site leaders.

... it's not for credit or anything; it is just to kind of get your feet wet and try to understand some of the personal and professional requirements of being an administrator. I went through the program a number of years ago and I think it was a good first step to thinking, 'well do I want to do this or do I not want to do this?' 
Both administrators and teachers were not able to specifically identify how their particular district engages in recruitment of site leaders beyond advertisements or informal networking practices. Teachers' had familiarity with how job openings are posted. All three teachers interviewed shared some vague awareness that jobs are posted somewhere so people know that the job is vacant. Additionally, they were aware of an application process involving submission of paperwork and interviews. Cat, a classroom teacher in Giada's district, also shared knowledge of how the district engaged in developing leaders from within.

I've seen the district do what might be considered recruiting new administrators in that they have created a cohort here in the district to train perspective administrators. An announcement was put out on the email that told us they were going to have a group of people going through administrative training in a partnership with [the local university].

Cat and Giada's district had a formalized structure that supports recruitment efforts by identifying potential candidates and providing the training necessary to make an informed decision about the realities of the job before making the leap to a school leadership position.

Informal practices spawning from formal structures benefited some of the participants in my study such as Emeril, a vice principal with nine years of administrative experience. He reported that his first administrative position came when his name was passed along to a professor in his administrative training program to the superintendent of a local school district through an informal conversation.

... but of course they get to talking that they need to interview for an open position. 'Do you have any candidates that are up and coming?' I think maybe he provided a list of people; my name was on the list. I got the phone call from the superintendent who invited me for an interview. 
This situation illustrates how superintendents in collaboration with local universities actively work to bring some of the best candidates to the interview process. It also illustrates how a formal administrative training system can promote the recruitment of skilled people through informal networking efforts outside the structure.

Another factor that impacts structural recruitment is the ability of teachers to move into positions of greater leadership. This is illustrated by the experience of Paula, a district resource teacher who coaches new teachers. Her story reveals how agency works in tandem with the structure of a resource teacher. She has systematically moved within the organizational structure of her district by applying for positions of increasing responsibility. These are teacher positions that call for some administrative and leadership responsibilities. Jobs such as site and district resource teacher, staff developer and new teacher mentor have given her an in-depth understanding of the complex role of a site leader. The skills and knowledge she has gained over the years because of the advancement structure that was available to her, (albeit a minimal structure), allowed her to pursue her desire to move into a site leadership position in the near future.

While teacher staff development created a structure that provided Paula with sitelevel and district-level understandings of full site leadership, this was not a recruitment structure for finding or preparing future principals. Nevertheless, those various positions combined with a teacher-mentor support system gave her experiences similar to those of a site principal.

The experience of Bobby, a classroom teacher in his fourth year, also illustrates how individual agency is crucial in a district organizational structure with ample opportunities but minimal recruitment structures. His site provided a structure for Bobby 
to take on the roles and responsibilities that would expose him to a variety of tasks and give him a broad view of site leadership responsibilities. Like Paula, his district valued collaborative decision-making and professional learning. This kind of experience gave Bobby the impetus to actively seek other experiences. "I was going out there and saying these are my strengths, these are what I know how to do, how can I get involved, who can I talk to in order to help in this aspect or in that aspect?" Bobby stressed his internal drive to affect "global changes in the educational system" and his desire to assume greater levels of responsibility. He appreciates the opportunity to work within a school structure that allows him to actively seek experiences that not only propel him into greater levels of responsibility but also give him the background necessary to make an informed decision about his career path.

I have been working a lot behind the scenes....In the past I was doing more presenting, more taking an active role and....I was kind of training people and helping people facilitate better staff development trainings.... I have also been trying to get more involved in the parent aspect, the parent involvement programs on this campus....I have also been shadowing all the assistant principals as well as the principal.

Bobby is self-motivated to broaden his experiences by stepping out of his

classroom to lead professional development and job shadow. He is actively grooming himself to assume an administrative position. He has a vision of the experiences he needs to make an informed decision about his career path and through self-promotion is using the organizations' structure to place himself in situations that support his career goals. In contrast to other teachers, he is beginning to develop mentoring relationships, but through Bobby's own admission, in his short career he has not developed a network of people who are working to keep him informed of career opportunities. 
Administrators interviewed thought the best training for school administration was through organizational structures that allowed for increased levels of responsibility. They stressed the importance of on-going leadership training wherein potential candidates could more easily move into administrative positions. When districts provide a structure of opportunities for leadership, attention can be given to grooming the best candidates through a gradual increase of responsibilities. This structure is a capacity building system that fosters recruitment within the district, but it is not a formal recruitment structure adhered to uniformly at all sites as evidenced by Ina's lack of recognition of this process.

\section{Culture}

\section{Informal Mentoring}

All five administrators interviewed shared knowledge of informal and formal methods for recruiting personnel to fill administrative vacancies. The depth of knowledge about district policy and practice was limited to their own personal experience in having gone through the application and/or selection process to move into their current positions. While formal recruitment practices were salient, knowledge of informal recruitment practices - particularly informal personal mentoring - emerged as the major conduit for movement into administrative positions, as reported by three of the five interviewed administrators. The depth of this knowledge about informal recruitment practices however, varied across districts and was specific to individual experience. The cultural norms that perpetuate informal recruitment practices, or networking and mentoring systems, had a significant impact on those who assumed site leadership positions. This 
was particularly true when informal conversations functioned to steer people to advertised job openings. Informal conversations not only served to expose potential candidates to people who are in a position to fill administrative vacancies but informal conversations also functioned to bring candidates to the selection process who otherwise may not have had knowledge that a vacancy existed.

Tyler, a veteran administrator of six years, shares how he experienced recruitment and selection practices in three different districts. He spoke generally of the way position postings are the primary tool used to solicit applicants. However, he also noted that district organizational culture that actively, albeit informally, recruits qualified candidates affects who apply for positions. He pointed to the actions of Assistant Superintendents who would call him and say, "We've got an opening at this school or we've got an opening at that school to raise my awareness and push me to apply." This kind of direct intervention supports or perhaps supplants the more routine recruitment practices of posting or advertising openings. Informal communication broadens the base of awareness about administrative openings and thus increases the number of candidates in the selection pool. On the most basic level these informal conversations model a culture of mentorship.

Interviews revealed that mentoring was an important piece of the decision-making process that propelled a person to site leadership. Current administrators like Emeril had people who coaxed them into leadership positions. Giada was mentored by a superior to assume greater leadership responsibilities at school. Ina was mentored by a series of site principals. Mario was pushed into assuming greater responsibility by co-workers and 
Tyler was influenced by a father who was a teacher, principal and a district superintendent.

Giada, a long time educator with two years of administrative experience, began her administrative career at the encouragement of her site principal. Giada's initial goal was to gain knowledge and skills that would support her in making the transition to a site leadership position.

I remember I was sitting at my dining room table when my mentor, the principal, called me. She asked if I would like to be the categorical coordinator next year. I did not really know what that was, but I was willing to learn ... during that time I was finishing up my Master's degree and Administrative Credential. . . then one day I was talking with the assistant principal at [the] High [School] when she suggested that I apply for the intersession principal vacancy. She did not really want to do it again and felt I could use the learning opportunity. Then there was an opening at [a] High [School] to be an assistant principal and I took the acting assistant principal position for about a month while still doing the categorical job. I did not get the position, even though I was already in the job. However, I did get an assistant principal job at a school I did not apply for.

Bobby, a relatively new teacher, placed himself in positions of greater responsibility that, in turn, set up a mentoring association with his administrators. He has benefited from the relationships he has cultivated himself by gaining administrative experience that continues to develop his leadership potential. Bobby is unusual in that he aggressively and actively sought leadership experiences within the culture of his school. Each of the current administrators was supported by mentors throughout their teaching career. An organizational culture that fosters mentoring relationships serves to develop the leadership of teachers and expand the pool of experienced candidates. These mentors had a direct impact on the individuals' decision to move into school administration. Moreover, two current teachers in this study also expressed the importance of mentors on their current road to a principal position. 
A culture exists at Bobby's site that allowed him to gain an understanding of the Vice Principal role through "an apprenticeship that started last quarter.” Formal structures do not exist within the district to support this apprentice relationship, but rather an informal agreement between Bobby and his principal support his desire to gain further insight into the complex role of school leaders on his campus. He has spent time shadowing the Vice Principals and taking on some "back office" tasks. These new opportunities come on the heels of a series of instructional leadership experiences. Even though Bobby does not identify a specific mentor, the culture of mentorship allows him to work closely with his administrators and gain experience in a relatively risk free situation. By gaining some degree of experience through "apprenticeships" Bobby is supported as he acquires skills and knowledge in making his decision to move up the career ladder.

Paula was mentored by her administrator to participate in school committees that would broaden her experiences and impact a greater number of students. Paula's district has a strong focus on maintaining high levels of student achievement. The organizational policies and culture, therefore, fostered her knowledge and leadership skills. In her extensive teaching career Paula has successfully functioned as classroom teacher, site and district resource teacher and new teacher coach, exposing her to a vast array of situations and experiences broadening her leadership capacity. These experiences along with the support of mentors have contributed to her decision to pursue an administrative position within her district. She acknowledged the benefit of informal mentors on the way to a principal position but stressed the need for a formal mentoring system once taking on the task of leading a school. Paula understands the importance that 
informal mentors played in supporting both her leadership growth and successful transition into a principalship, thereby suggesting that a formal structure of mentoring will ensure a successful recruitment and retention of principals.

Like Bobby and Paula, Cat's current administrator identified her as a person who possesses the leadership characteristics necessary for successful site leadership. Moreover, Cat stated that "my principal has been nagging me to get an administrative credential." However, when asked if she considered getting her credential Cat responded:

It crossed my mind and I have had the opportunity to choose that. I just got my Master's this year. I thought about it, but for all these reasons I have told you, I just resisted it. I just didn't see anything attractive about the [principal] position.

Although her current principal acknowledges Cat's potential for site leadership, Cat has formed a strong negative opinion of the principal position as one with a very narrow role. The context in which Cat has formed her mental image of the positions has been devoid of any mentoring relationships. The administrator in Cat's district participated in this study and stated that the previous district culture supported leaders who modeled operational tasks as a priority. For Cat, this was hardly an attractive role. However, a cultural shift occurred in Cat's district and leaders began to focus on the improvement of teaching and learning in order to raise student achievement levels. This shift in responsibility is not consistent with the image Cat has of the principal's job. She was not interested in the position because she still saw it as a director of managerial tasks, such as coordinating tests, ordering equipment, evaluating teachers and maintaining student discipline. Cat participated on site level committees that should have broadened her view of the principalship. However, the culture of her school did not function to build 
her vision or leadership capacity by providing experiences that would broaden her understanding of the site leadership role.

Cat's limited view of the principal position comes from an experience devoid of mentoring between Cat and site/district leaders. The continual change in site leadership in her seven-year teaching career has contributed to the difficulty in establishing a mentoring relationship. Such mentoring would expose her to the multiple roles and responsibilities of the position beyond disciplinary issues and/or site operational activities. When mentoring is absent and potential administrative candidates experience a poor model of leadership, they understandingly choose a career path away from site leadership. A mentoring relationship with site/district leaders is critical to revising Cat's vision of her place as an educator, particularly if her administrator believes that Cat has the traits for successful leadership. Furthermore, a formalized structure of mentoring would engage a potential leader like Cat, rather than an ever-changing leadership that repulsed her.

Site administrators easily identified the knowledge and skills in teachers they would chose to mentor - traits necessary for effective site leadership. However, only Giada talked about the mentoring necessary to build leadership capacity in teacher leaders that will put them on the path to a principalship.

I work with qualified people here at my own site every day and I think we need to figure out a way to access that talent and the pool [of candidates] that already exists on our own sites. I think that I might do something like get that person a substitute and have her shadow me for a day. I really don't think that people have a clear sense of what the job entails and I think that makes it scary to some people who might personally be totally qualified to do the job.

Giada has a vision for mentoring teachers who have the potential for site leadership but she has not internalized how to connect with staff members in a way that 
will build their capacity for increased levels of responsibilities. The lack of connection with staff members who would benefit from her mentoring can be attributed to her short tenure - one year - in her current administrative role. With time Giada should be able to develop the teacher mentoring relationships she desires. However, a district should not depend on an administrator to eventually "catch on" to mentoring practices for developing district leadership —a formalized structure for mentoring would help Giada ease into mentoring and recruiting.

\section{Leadership Models and Skills for Effective Leadership}

The models of leadership presented by current administrators are key to how teachers view the principalship. Teachers' perceptions of the qualities necessary for effective school leadership differ due to their varied levels of awareness about the responsibilities of a principal. Teachers held radically different pictures of the work of site administrators based largely on the behaviors of administrators they experienced during their careers. These experiences and perceptions constructed their notions of effective leadership. When there is a disconnect between teachers' opinions about effective leadership traits and the leaders they experienced in the past, mentorship becomes even more critical in developing them as potential leaders.

Mario, a site administrator, believes that teachers see "a principal's role as a visionary who fosters collaboration among a wide variety of stakeholders while navigating the politics of an educational system and still having enough time and energy remaining to manage the operational aspects of a school site." Cat agrees in theory with administrators and teachers in the study about the qualities for effective site leadership, such as "the ability to foster leadership in others," "the ability to motivate others towards 
a common goal," and "the ability to look for innovative ways to work with changes that are constantly occurring in education." Yet Cat was unable to articulate these traits when discussing her past and current principals. Because of multiple changes in site leadership, Cat cannot construct a realistic vision of what makes a successful leader with the models she has observed.

Articulating characteristics and traits necessary for effective site leadership was easier for current site administrators than teachers in the study. This can be attributed to the internalization of the traits: current administrators believe they embody and routinely exercise those traits. However, teachers in the study have a vision of a good leader but they may not actually have experienced these traits in themselves and/or in someone they worked under. One glaring example is that less than one percent of teachers, either surveyed or interviewed expressed "the ability to make decisions" as contributing to effective leadership.

All participants - administrators and teachers - ranked effective communication skills as the most essential quality for successful school leadership. One respondent noted that effective communication is evidenced by a person who has the "gift of gab and [the] power to motivate." Half the participants felt that in addition to being an effective communicator, a leader must have the ability to foster relationships and posses a strong knowledge of instructional pedagogy. There was a surprising lack of emphasis from current administrators $(25 \%)$ and teachers $(0 \%)$ on the need for site leaders to posses a high level of integrity or a strong belief system relative to educational practice. These two characteristics are important factors in keeping a leader grounded under their accountability and political pressure. As Mario, a site administrator, asserts, "Kids are 
often exploited for political purposes and for people's careers." Further, Emeril declared that "an administrator must stand his/her ground with people who appear to have agendas." Survey responses also emphasized the belief that an administrator must maintain objectivity and not take things personally. Participants who included integrity and a strong belief system as important characteristics stressed that these are best modeled by someone who is fair, consistent, and honest with staff and who employs an open decision making process.

Consistent communication can be the most difficult aspect of a principal's job, noted many participants. It means dealing with the personalities of teachers and fostering genuine relationships with teachers, students, and parents. Some believed that a leader has a responsibility to get along with everyone while also cultivating relationships in which everyone strives to work together as a team.

Ina asserts that fostering relationships allows principals to find support for a whole host of tasks that fill a site leader's day. Collaboration is a natural by-product of relationship-building and supports the work of organizing instructional and operational tasks. Leadership that models a collaborative environment presents potential leaders with a broader vision of the principal's role. In essence, an administrator need not be alone in coordinating staff development. By bringing teachers, counselors and support staff together, a structure is formed within the school culture that allows for collaboration, a division of the work and the mentoring of potential leaders.

Giada asserted that a site leader must understand that an optimistic outlook toward people is a necessary first step to effective communication. One survey participant 
emphasized that a positive approach to communication, even when disagreements arise, fosters mutual respect and/or understanding:

At the very least, each person walks away knowing how they disagree and the position that's taken by one another on a matter. As long as you were open to listening to the opposing position and understand it and remain opposed to it, there is no shame in choosing to remain in disagreement.

Although disagreement may result from communication, leaders who nurture a strong interpersonal relationship with staff will have a group who work as a unit in support of the principal. The importance of communication and interpersonal skills was evident throughout the data and indicated that it was perceived as a key component to effective leadership. Further, a site leader must use a positive and optimistic communication style in all endeavors in order to keep people comfortable in their work relationships.

Attending to the health of relationships fosters opportunities for mentoring that support movement into positions of growing responsibility. Teachers' perceptions of traits that lead to effective leadership, coupled with their development of these traits through informal mentoring, influences their decision to pursue administrative positions. Further, the development of effective leadership traits in teachers supports a district's recruitment efforts by increasing the pool of potential administrative candidates.

\section{Recruitment: Diversifying the Leadership Ranks}

Respondents believe districts are doing a better job than in the past recruiting people of color and women into leadership positions. However, some administrators and teachers report frustration about their organizational culture wherein people are sometimes promoted based more on relationships than ability. Some respondents perceive that, in an effort to expand the diversity within the leadership ranks, promotion 
is based on friendships and/or ethnicity, rather than skills or qualifications. This perception plays a significant role when recruiting people into leadership positions.

Three of the five administrators interviewed obtained site leadership positions through an informal process arising out of relationships. They note that a district culture that relies primarily on an informal process fosters the movement of people into administrative positions. But relying on relationships as a primary recruitment process, they worry, perpetuates a new type of "good old boys network." Who gets tapped for positions seems to be highly discretionary and very much tied to the race and gender of the mentor. Administrators in this study perceived that sole reliance on networking may lead to diverse representation but not talent. Giada shared her concern when she stated, "I think our district is doing a better job now of encouraging the recruitment of administrators who reflect the [ethnic] community which they serve, but I think we really have to be aware of not going too far the other way and hiring people for the wrong reasons." The implication is that ethnic representation is not necessarily helping the district or students of color when site leaders do not posses the skills and experience necessary for improving student achievement. Administrators and teachers across districts contended that an unspoken culture is present that supports the need for a leadership team that is diverse both in gender and ethnicity throughout the district. But this culture has led to a perception that recruitment practices rely heavily on a network that emphasizes race and gender, rather than leadership skills and knowledge.

Administrators and teachers agree that "who you know" has a profound effect on who gets recruited for site leadership roles. This perception is particularly true in the areas of recruiting persons of color. Emeril, a Hispanic site administrator, perceives that 
his district and "local city government" hire individuals with the specific intention of moving Hispanics into top leadership positions. He asserted that by placing people in leadership positions "who represent the ethnic diversity, the majority group of people will feel connected to those in power and in turn feel that those leaders are working in their best interest." Like Emeril, Bobby, a Filipino teacher, is conscious that his ethnic background supports diversification in his district, and he expressed the potential benefit that his ethnicity had in his ability to advance to positions of greater authority within his district.

All respondents are of the opinion that race is a more significant factor in recruitment and hiring than gender. Bobby feels that his district is "looking for administrators [and teachers] who can better connect with the students." He translates this connection in terms of race. "The fact that I am [of a specific race] would definitely help [me] achieve my goals in the hiring process because they are looking for diversity in this district." He argued:

In regards to credibility, it's sad to say but I know it's true, people who are Caucasian in this district do not have as much credibility as administrators who are an ethnic minority. It is not because they are not qualified or really good at the work they do, but they have to prove themselves more to the students as well as the staff to show that they do understand the plight of the students and they are really here to help students. People who already are minorities are kind of assumed to have baggage already because a lot of the people who came to this district have come from a similar association of background so there's an easier credibility. All you have to do now is make sure you don't do anything too horribly bad and just keep on doing well.

Bobby and Emeril both said that their minority background was an asset in the recruitment process for administrative positions. Further, they felt that the district culture supported their respective desires for greater influence through assuming leadership roles. 
Bobby stressed that while diversity was a priority in his district, being "able to speak two languages is even better."

Paula, a mentor teacher, believes that her district talks about diversifying the administrative ranks but continues to select candidates who "look" like the majority white population. Bobby, when asked about his perception of the need for diversified race and gender leaders in a district like Paula's, which is primarily white, said that it is only an issue in some districts.

I would guess that gender and ethnicity would not play as large of an issue as it would here because you do not have as large an ethnic population. It may lack as many disadvantaged [students], or English Language Learners with reading levels below grade level. Because of factors such as these, I do not think ethnicity or gender would play a huge role compared to [my district].

Like Paula, other participants stated that their districts are making concerted efforts to diversify their administrative ranks, but felt that an underlying culture exists within their districts. Hiring practices in Paula's district that continue to fill vacancies with "white" candidates do not support the organization's attempt to diversify the leadership team. Giada asserts that her district, with a large Hispanic population, has worked to fill administrative positions with those whose "outward appearance reflects the community which they serve." While on the surface Giada, who is white, supports this practice, she did express concern for the potential problem of selecting unqualified leaders when those who make placement decisions go too far in their efforts to expand the diversity and begin to hire people based solely on race.

The white participants in this study discussed the effects of relying primarily on informal processes that supported the recruitment of administrators of color. Tyler, for example who is a white male administrator in a district with a large second language 
population, explained that the pressure to diversify the leadership pool across three districts in two different states impacted his ability to move into school administration. Tyler stated that in a state with a high Latino population other than California he was told that the district was focused on promoting school leaders of color.

I applied and interviewed [for an administrative position] in another state. I was told that they were top heavy with white males in administration, that they probably wouldn't be hiring any more white males and that I would probably need to leave the district to get administrative experience and then come back. That told me 'thank you for spending your entire teaching career with us, but that's as far as it's going to go.' Additionally, I felt the focus was on promoting African-American and Hispanic females. It was very obvious. I knew teachers who were African-American and Hispanic who were approached to go into administrative positions. From that pool, there were even several people that I worked with that were principals and assistant principals that I felt were very incompetent. After being told I would not be promoted based on a race criteria I often wondered if promotions were because of gender and race rather than skill or ability.

This point of view is not isolated to specific states or districts. Emeril, a Latino

male, believes his district, located in the southern portion of the county and state, actively sought to fill leadership positions with Latinos. He believes that his district hires Latinos above individuals from other ethnic backgrounds. Some respondents argued for the importance of such an informal process because the recruitment pool is unfortunately absent of diverse candidates. According to Emeril, if we are to meet the demands of an entire community such action is necessary. In fact, as Ina, an administrator in a primarily white district points out, even when deliberate action is taken to recruit individuals of color, the applicant pool is still unmistakably white.

This district is probably fairly balanced in age and gender, but definitely not by ethnic backgrounds. I would say that we have our own internal barriers to that. I was not in on interview pools, but last year they had consciously recruited some diverse candidates to apply for assistant principal positions. There were maybe nine candidates; at least three were diverse candidates. Using the group interview process at the district office, none of those three were recommended to go on to 
the superintendent for final review. So even within our system, even when we consciously recruit diverse candidates, we have barriers in place in the room that I think prevent them from moving forward.

Bobby, a Filipino, has a strong belief that "you have to know the population you are working with," which requires leaders who "look like the students." Cat, a white female, feels that race is a significant factor when promoting and/or selecting candidates to fill administrative positions.

I see the district and I see people in the district being promoted based on their ethnicity, or whether they're in a certain 'good old boys club' [based on a common trait of race] not based on their ability. One of the principals we had was a member of that club and keeps getting advanced although there is hardly a teacher in the district that would work for him. [He was Hispanic] We also had a brand new assistant principal; she was Hispanic and got promoted to a middle school [principal], not even having done a full year as an assistant principal. There are assistant principals who are white, black and Filipino that have been working in place for a long time. I wonder why they didn't take our other assistant principal with a lot of experience and put him in a principal position. The perception that goes around this district is that you have to be Hispanic to get promoted. Part of it is a Hispanic background, but also being able to speak Spanish is important. Obviously, we have a white principal here, but she does speak Spanish. We have a $60 \%$ Hispanic student population, so it is beneficial and it is important to be able to speak Spanish, but it should not exclude good people from getting administrative jobs.

Respondents expressed concern for solely relying on networking systems to advance diverse but unqualified people to leadership position. Many felt that informal mentoring relationships established through networking systems strongly determine a person's decision to pursue a leadership position within a district. Mentorship once again surfaces in this study as the salient force in recruitment, motivation to advance and even serves to discourage candidates based on race/ethnicity. The negative perceptions that individuals are too often promoted based solely on race could be avoided with a formalized structure of mentorship. These mentor-mentee partnerships can serve to 
train and promote a pool of racially - and gender - diverse candidates who assume leadership based on experience, skills, and knowledge.

\section{Agency \\ Factors Influencing Movement into Leadership \\ Personal Ambition.}

The actions individuals take as they begin to move into site administration is strongly influenced by the structures and culture within a district. These structures (advertisements, job announcements, informal conversations, and positions of growing responsibility) and organizational culture impact who is recruited or who is not. Administrators and teachers expressed concern that their district culture promotes a new type of "good old boys" network based on relationships built upon race/ethnicity. That said, it was the initial motivation and action to pursue administration by individuals that strongly influences who was recruited. Individuals had the desire for a broader impact on student success or upon education in general. Ina, an experienced administrator, initially pursued a Masters in Educational Administration "not necessarily knowing that [she] wanted to be a school site administrator but knowing that the administration credential was the ticket to curriculum positions and other like positions" that would influence a broader band of students.

Both Bobby and Paula possessed an understanding that as school administrators they had a wider scope of influence on the educational process for all children. They differed however in their early attitudes about seeking leadership positions. Bobby knew before entering the teaching profession that his movement into administration was 
inevitable. He believed that teaching was a short-term goal and becoming a school administrator supported his long-term goal of a researcher focused on "unlocking the secrets of education for the neediest children." Bobby took action early toward establishing an administrative career. His ideologies and beliefs about leadership and its potential impact on children guided his actions for practical experience in site leadership responsibilities. Bobby continues to work to gain knowledge and skills about leadership by participating in "apprenticeships," site level professional development and committee work. Such experience decidedly supported his ultimate decision as to whether to pursue a site leadership position or to help impact student success in another capacity.

Early aspirations to create "a global change in the educational system" inspired folks like Bobby and Paula into education. Bobby went further to state that he "knew that teaching was just the first step [towards achieving his long term goal]." By contrast, Paula, currently a district resource teacher, did not give any thought to the possibility of entering administration before starting her teaching career. Mentoring empowered her as a teacher, and she decided to assume greater levels of responsibilities. She changed her goals to impact a greater number of students on a grander scale. Paula experienced the power of mentoring as a motivation for site leadership. The culture of informal mentoring provided Paula with the experiences that developed her leadership and prompted an evolution in her career plans towards seeking site leadership.

Assuming greater responsibility in the educational system allows individuals to have a greater impact on student achievement. Personal experience provides the broadest understanding of the school administrator's role. Agreement exists among all participants 
that a strong motivator for career advancement is the desire to have a greater impact on students. Tyler, a principal, affirmed:

I wanted to go into administration because I wanted to make a difference; I had worked with principals who I felt were ineffective and who didn't have a clue about teaching or about kids. I wanted to be different. I wanted to be an advocate for teachers. I wanted to be an advocate for kids. At the same time I wanted to be able to say to teachers, 'Here is what is going on in your classroom, is it effective or not effective and how can you then take what's not effective and make it effective for kids.'

The desire for a global impact was not felt by all teachers in the study. Potential leaders are discouraged by models that narrowly reflect the realities of site leadership such as: the stress of spending the day dealing with major operational issues, including discipline; the long hours for little pay; and the supervision of evening events for no extra compensation. Of the thirteen teacher surveys analyzed for this study, Cat presented the sole perspective of maintaining her status as a classroom teacher even though she was identified by her current site administrator as someone who possesses the traits that would make her an effective principal. Cat was adamant that she had no interest in leading a school site, then or in the future. She asserted that she would "rather be in the classroom. What I see [principals] do in general is just not what I want to spend my day doing." Cat never entertained the possibility of a site leadership position. She explained it this way:

I'd rather be in the classroom with the kids. Honest, I believe that I have some really great leadership qualities, I could lead in a lot of ways and I'm very active in a lot of the committees on campus. But, I just don't see administration as where I want to be. I don't even see the job that the principal does as very interesting.

Cat was definitive in her lack of desire to take on the burden of school administration. Cat's lack of desire for career advancement is attributed to the culture of site leadership that is singularly focused on the task of disciplinarian and coordinator of 
administrative tasks such as "the headache of administering the major test that we have to do." That leadership model, inconsistent with her ideas of effective leadership, coupled with the lack of a culture of mentoring during her teaching tenure, was significant in discouraging her from pursuing school leadership. However, her personal agency played a role as well— her lack of ambition to play a larger leadership role on her site or within the district, or her own sense that administration is not a "fit" for her also contributed to her decision not to pursue a principalship.

\section{Impact of Leadership Models.}

As teachers move from school to school they are exposed to an assortment of leadership styles which impacts their decisions to effect change at a level outside the classroom. These evolving models influence a person's perception of who they should be as leaders and whether they are willing to assume the growing burden of leading a school. As Bobby recalls:

I thought to myself, 'could do a better job than these guys can if I were given the opportunity and the training?' Knowing that there are things I would change to make the school run differently and seeing the people currently in these roles and believing that I could do a better job have made me want to go into the field of administration faster."

Bobby and Paula, who have a broad view of the multiple roles that come with site leadership, have been exposed to leaders who model the balance between operational and instructional tasks. Where Bobby and Paula envision site leadership as a combination of administrative tasks and working with teachers to improve instructional practice, Cat has been presented with leadership models where principals attended primarily to operational tasks and where little or no time was spent working with teachers to improve instructional practice. When asked to detail the multiple roles and duties of a site administrator, Cat 
describes the principal's job as dealing with "non-compliant students," "irate parents," "testing," and "district mandates."

A culture that addresses teacher training and pedagogical development does not appear to exist at Cat's school. This contributes to her limited view of school leadership. This is evidenced by her prediction that "[she] would be happiest making a bigger difference by teaching teachers." Yet, when asked if she saw this as a role of an administrator she asked, confused, "to teach teachers?" In Cat's case, her perceptions have been hampered by multiple transitions in leadership in a relatively short period of time. This has led to an organizational culture that has shifted with each new administrator.

Each principal who comes to this site does not seem to stay very long. This makes it difficult to make changes in the way things happen. This person is always getting the students and parents in line, taking care of all the district mandates and the testing stuff from No Child Left Behind. They put in long hours but there is not much time for anything else. The principal's job is to make sure that teachers have the resources to teach, but even this is difficult when the district keeps cutting our budget.

Cat comments that with each new administrator she has experienced "how difficult it is to institute change." Cat's failure to envision the principal role as a teacher of teachers suggests that the culture that drives Cat's school does not foster an atmosphere of raising student achievement by examining how teachers teach. Further it does not appear to expose staff with leadership potential, such as Cat, to a broader spectrum of collaborative experiences that build an enhanced vision of the site leadership role.

Cat's exposure to three principals in seven years has contributed to her negative impression because the change process is slow. Principals leave the site for a new 
assignment before the gratification of improvement. The district recruitment structures, then, hindered both the campus culture and the personal motivation of skilled teachers.

[The former principal] came here, he was great, and everybody loved him. This campus rebounded. The staff came back together in a way that I had always heard they used to be and [we] really rallied behind him. He wanted to be here and we wanted him, [then the district] pulled him away from us. We were barely recovering. We were healing, we were building and all of a sudden they pulled the rug out from under us. The man had one year left before he was going to retire and they decided to move him to a high school.

Cat's current site administrator assumed her position after the departure of the favored leader and is in her first year at the site. The rapid turnover in site principals has brought with it three different leadership styles and priorities. The impact of the administrator changes has left Cat angry and feeling as though she does not have the resources she needs to accomplish the job. Therefore, it is difficult for her focus on a more positive image or foresee any desirable aspect of the job for herself.

In contrast to Cat, Bobby and Paula have been presented with leadership models that demonstrate the variety of responsibilities common to that of leading a school with a mix of instructional duties and managerial tasks. Both teachers have at times entertained thoughts of "I can do a better job than this principal," and yet, over time have been presented with role models that they would emulate. Factors that motivate the desire and willingness to lead a school site are multi-layered. Administrators in the study reported that their motivation came from a personal belief that they could do better than the administrators for whom they were working. For Giada, the motivation came from wanting to effect change for children on a larger scale than her current position allowed:

Originally I thought I wanted to be a school psychologist and that was my background. I thought that was what I wanted to do and then I realized that they did not have the influence and the ability to change the system. I was at that time 
frustrated with the system and I thought 'if I'm going to make a difference then I need to be the boss' so I decided to be an administrator instead.

Because of Cat's serious dissatisfaction with her site leader(s), she was not enticed to "do a better job" by leaving her role as a classroom teacher to be a school administrator. However, Giada, a new principal, describes her experience as a teacher and speaks to the need to encourage those like Cat who have the potential to assume leadership roles outside of the classroom, particularly as teacher leaders responsible to their peers.

I think part of this goes back to teachers not seeing themselves as leaders of other adults. I think teachers see themselves as leaders of kids. I was a teacher for many years. I felt I was a successful teacher, had a good rapport with my kids, and covered the curriculum. It was not until I got onto the School Leadership Team for my site that I learned more about things other than those I was doing in my classroom. It helped me to see myself as a possible leader of my peers. With the ongoing support of mentors, I became a teacher leader at that point and from there administration was a natural step.

Family and Community Influence.

Another motivation to lead is inspired by family. Families provide assistance with a person's internal struggle to maintain objectivity and not take things personally in a demanding job. Emeril describes how his wife put things in perspective for him as he struggled with the decision to enter an administrative credential program. He could not imagine pursuing a career path that would lead to a job he felt was "nothing but a bunch of headaches and no one likes [administrators]." His wife helped him to understand that his negative impression was a natural view but should not prevent him from pursuing an administrative position.

You should see how some teachers talk about administrators, it's like they are separated from the rest of the staff. It does not seem like they are part of us [other teachers]. It is almost like a them against us attitude. My wife heard me out and than she said, "not everybody is ever going to like you $100 \%$ of the time. There is 
always going to be people no matter who you are that will disagree with you or do not like you, but this should not prevent you from advancing your career."

However, family influence manifested differently for Bobby. He emphasized that the most significant barrier to his taking on a principal position is his commitment to family. He shared, "I have seen [principals] who are very successful in regards to student performance, rapport with staff members, and the vision at the school. But they're here at work at 6:00 a.m. and they leave at 9:00 p.m." He stated, "My family is and will be the most important thing in my life," and "I will not sacrifice my marriage or watching my children grow up to advance my career." Bobby's commitment to his immediate family impacts his career path decisions. His reflection that principals often put in fourteen hour work days discourages his desire to assume school leadership responsibilities. If Bobby continues to believe that long hours are a requirement for successful leadership, he could ultimately decide he is unwilling to choose the demands of a principalship over quality time spent with his family, regardless of district recruitment efforts.

Like family, individuals' communities also motivate teachers to lead. Emeril, a site administrator, was guided into a site leadership position by a need to be a role model for the Latino community:

I was really trying to personally do something for my people. I know that being a Latino male there were very few of us in the field and I knew that we were really being recruited. Certainly when my wife started naming my qualities as a person, and why she thought I would actually be a very good candidate, she listed my positives. She listed the fact that first I am a Latino and male. 'There are not many of you out there that the kids can look to as positive role models.'

\section{Growing Demands: Age of Accountability}

Potential school leaders can be discouraged from leadership due to a political climate that places growing pressure on leaders for student success. The accountability 
pressure placed on leaders, particularly from the No Child Leave Behind Act (NCLB) (1993) did not discourage administrators or teachers in the study from thinking about a principalship. Administrators interviewed spoke positively of their roles as school leaders even with the growing responsibility for raising student achievement. This indicates that teachers' perceptions of the demands placed on principals are not as critical to his/her decision to assume as site leadership as the impact of mentors who are modeling the positive challenges of the job.

Four administrators spoke positively about the current focus on accountability systems to raise student achievement levels. All agree that accountability systems bring more political pressure that contributes to the difficulty of the job. Ina, who has twelve years of administrative experience, emphasizes that things have changed over time: "everything about education has changed tremendously in twelve years; the accountability piece has been a huge change factor for all of us." Additionally she adds, "Parent expectations have increased I think. The role of special education is huge now and twelve years ago that was very much a small part [of a principal's responsibilities]."

Giada asserts that "someone who wants to go into administration has to know above all else that student achievement is the most important thing and I mean for all kids." She speaks for the majority by sharing that, “ NCLB is a very uncomfortable law to live with in the way that kids are moved around and money is moved around and all that, but it's really a step in the right direction as far as addressing the needs of all kids." However, Mario, whose school is considered to be high performing, almost discounts the reality of NCLB's impact;

I often hear people say I wouldn't want your job for anything. It always surprises me because it's a great job. I rarely feel any sort of stress. I don't have long 
hours, I don't work long hours. It's rewarding financially. So I understand I think when teachers say I wouldn't want your job, it's usually in the middle of some kind of a temporary crisis that from the outside looks difficult to wrestle with and maybe if I'm being more honest, it is difficult in the moment and stressful in the moment, but it passes and then we have days like this where I can sit and talk to you, but I don't have very many stressful days.

Mario's longevity at his current site may be a contributing factor to his feeling of not having "very many stressful days." He did speak of the first three years at his current site being a time of turmoil and conflict. Further, he shared that problems do arise that present stressful situations and that require problem solving on his part. In general he did not experience the long hours and accountability pressure that is often heard from other site administrators. This may be attributed to the structural design of a charter school. A charter school, by design has the freedom to design an educational program that functions outside of state-established education codes, district policies and the influence of teacher unions. In addition, the governance structure requires a shared leadership model that addresses issues of student achievement. Mario embodies the leadership of “collaboration" identified by survey responses. He functioned within the culture of the campus to facilitate high quality teaching and learning but that high quality is a shared responsibility.

Tyler, also a charter school principal, countered Mario's perspective with knowledge of friends and colleagues who are leaders at schools identified as Program Improvement ${ }^{6}$ under the No Child Left Behind law. He shares the difficulty expressed by others:

We're trying the best that we can; we're doing all of this. We've got staff development in place. We're talking about kids work. We're doing this. All of this stuff and [they are] still struggling with being a 'Program Improvement'

\footnotetext{
${ }^{6}$ Schools are classified as "program improvement" under NCLB for failing to meet state established student achievement levels for two or more consecutive years.
} 
school. That has to be very frustrating to know that you've done it, you're trying, staff is working hard and you can only do so much. You try to change every kid, but that's hard. I think sometimes it's very lonely because you can't sit and have a conversation like this on a day to day basis with somebody.

While there is consensus among administrators that accountability systems add pressure to an already demanding job, they were strong advocates for these systems as one vehicle for monitoring high quality teaching and learning within the educational system. Ina stressed that they have in fact had a positive impact on teaching and learning as her teachers know "so much more about students." She sums up accountability systems by emphasizing that it is "less about feeling good and more about doing good." Despite the fact that pressure for accountability was not identified as prohibitive to career advancement, the mounting workload that comes with increased accountability was forefront on some administrator's minds.

\section{Conclusion}

An organization's structure and its culture were interrelated in the recruitment process described by the participants in this study and were often difficult to separate in the discussion. Moreover, an individual's career choices are highly dependent on the interaction between the organizational structure and culture. An organization's leadership culture was shaped by the structure of the district's policies and procedures, especially regarding their formal recruitment methods. Administrators and teachers in the study shared only surface-level knowledge of job openings through announcements, job fairs and email communications. Administrators' knowledge was limited to personal experience, yet teachers had a vague awareness that districts have a process for posting vacancies. This limited knowledge hindered district recruitment efforts to bring to the 
selection process a comprehensive and qualified pool of candidates for leadership opening.

District structures enhanced leadership skills by providing opportunities for teachers to assume positions of growing responsibility such as: participation on committees, site or district resource teachers, and an intersession or summer school administrator. It supported recruitment by developing potential leaders from within the organization. In addition, a district structure that partners with a university training program to expose potential leaders to the roles and expectations of a principalship provided a formal network for mentoring potential leaders.

As significant as the formal structures were in recruiting individuals, the effectiveness of those structures were dependent on the informal recruitment methods evident in the district. Administrators and teachers identified informal mentoring as the major conduit for the pursuit of school leadership. Tyler, a veteran principal, addressed the need to build "...teacher leaders on campuses and recruit people for administrative positions because they know the curriculum, they know the kids, they know the ins and outs of what works and what does not. Those are the people that we need to mentor into administration." Mentoring relationships were particularly critical in the absence of quality leadership models.

While mentoring relationships created a productive culture of informal networks, respondents also raised concern about the networks themselves. A different kind of "good old boys" network has evolved, they said, but not one exclusive to white men. Instead, administrators and teachers perceived that in the effort to diversify, district leadership may have privileged candidates' race or ethnicity over individuals' leadership 
traits and skills gained through experience. They believed that less than qualified leaders were selected who negatively impact student achievement.

Many factors contributed to a person's motivation to move from the classroom into school leadership. The data presented suggest that factors such as personal drive, family and community influence, response to mentors, and a desire to have a broader impact on student success provides the impetus to seek greater levels of responsibility as a principal. However, structures and culture impact a person's ability to gain the experience and exposure necessary to assume a principalship.

This study reveals that formalizing the current culture of mentoring is key to finding a greater number of potential leaders. By formalizing the mentoring process, district policies and procedures function to recruit more outstanding mentees and place them into the much-needed administrative positions. Data in this study also revealed a list of leadership skills that both teachers and administrators perceived are necessary for effective leaders. By formalizing mentoring practices, administrators can be trained to more consciously recognize these traits in their staff members and bring more individuals into both the mentoring and recruitment processes. 


\section{CHAPTER 5}

\section{DISCUSSION, IMPLICATIONS AND RECOMMENDATIONS}

In fact, leaders... that go from good to great start not with 'where' but with 'who'. They start by getting the right people on the bus, the wrong people off the bus, and the right people in the right seats... first the people, then the direction. (Jim Collins)

\section{Introduction}

Nationwide, districts are facing the daunting task of filling administrative vacancies at a time when the pool of qualified candidates is decreasing. Researchers predict that administrative vacancies will increase by as much as twenty percent. Some estimate that half of all principals will be eligible for retirement in the next six years. (Hertling, 1999; Levely, 1999; McCreight, 2001; Peterson \& Kelley, 2001; Gates, 2003; The Wallace Foundation, 2003). At the same time, there is growing concern about the demands of the job that prevents potential candidates from applying for administrative positions. Districts across the country have the unique opportunity, but also the significant challenge, of recruiting, selecting and training an entirely new group of leaders.

Filling vacancies with skilled and knowledgeable leaders is critical, as those selected have the potential for impacting schools for decades. The national sense of urgency to raise student achievement makes it difficult to recruit leaders who are responsible for student success at their school sites. Researchers are split as to the reasons why more talented people are not applying for leadership jobs. Many researchers believe that the complex and demanding role of today's principal keeps individuals from pursuing the job (Hertling, 1999; Levely, 1999; McCreight, 2001; Peterson \& Kelley, 
2001; Whitaker, 2001). Whitaker's ${ }^{7}$ (2001) research also indicates that constant stress (emotional, cognitive, and physical) discourages individuals from pursuing site leadership, and incommensurate salary levels for the position's responsibilities is discouraging as well. Despite these assertions, in this study stress and salary surfaced only as a minor factor for study participants in their decision to seek a principalship.

\section{Summary of the Study}

The purpose of this study was to identify the structural, cultural and agentive factors that influence a person's decision to pursue an administrative position.

Determining the factors that impact a person's decision for leadership is critical if districts are to design and implement recruitment practices that bring the most qualified candidates to the selection process.

A mentoring culture and organizational structures for gaining administrative and leadership experience are interdependent: both are crucial for successful identification of candidates and their subsequent advancement. Yet at present, a mentoring culture is primarily informal at school sites, and recruitment is left to chance. This study aids our understanding of the current leadership shortage and helps identify recommendations for improving the qualified candidate pool. Specifically, this study shows the need for districts to provide a structure for mentoring as a method for both training and recruitment rather than depending on an informal culture of mentorship to encourage individuals with leadership desires.

\footnotetext{
${ }^{7}$ A study conducted by The Educational Research Service performed (2000) for the National Association of Elementary School Principals and the National Association of Secondary School Principals
} 
A key finding in this study is that informal mentoring relationships exist across districts and serve as the driving force in propelling new and experienced teachers into administrative roles. A person's desire to impact student learning in a leadership capacity is often the impetus for career advancement, but the actions taken to make this leap are heavily dependent on the structures and culture of the district and school site.

Two additional findings in this study will also inform districts' policies in leadership recruitment. One is that participants revealed strong emotions around promotion based on race or ethnicity factors, rather than qualifications. Whether or not this perception is accurate, districts are losing potential candidates who believe they will not fit into the new version of an "old boy's network" that is based on race. There must be a system in place to guard against the perception of this new "exclusive minority" network when elevating people to leadership roles.

The third significant finding is the list of skills that teachers and administrators believe are necessary in effective leaders. Based on the administrators they observed, some participants felt that they could do a better job than administrators who lacked those skills. However, when teachers with leadership potential experience poor role models leaders without traits deemed important - and experience no mentoring for advancement, they chose a career path away from site leadership. Crucial to participants' desire to enter into leadership, then, was both the positive and negative leadership models they encountered as well as their experience of informal mentoring within the district culture. 


\section{Discussion}

The two research questions for this study are interrelated and discussed together: What structural, cultural, and agentive factors motivate movement into positions of school leadership? What structural, cultural, and agentive factors discourage movement into leadership positions?

\section{Organizational Structures}

Organizational structures provide a system for teachers to acquire skills and knowledge necessary to successfully transition into a site leadership. Formal structures that moved individuals beyond the confines of the classroom included: participation on site or district committees; becoming a site or district resource teacher, staff developer, or dean of students; and coordinating and providing adult learning. These roles provided specific training to develop skills and responsibilities. In addition, the experience provided an understanding of the principal's role. All study participants, whether a current administrator or teacher, to some extent have within the structures of their district a means to gain a more global insight about student achievement. They have been able to gain experiences that led to the decision to assume the demanding role of a site administrator. However, the critical decision-making factor among the administrators interviewed in this study was the support of informal mentoring relationships that happened outside of district structures. Informal mentoring also affected the timing and method of moving within the organization to a site leadership position.

Developing recruitment practices that successfully increase the pool of qualified candidates for school leadership is dependent upon factors that motivate people to pursue school administration. In addition, potential candidates can only apply for administrative 
vacancies if they know about them. Current administrators in this study complained that traditional district recruitment practices that brought each into the selection process were limited to job advertisements and word-of-mouth. Teachers had little knowledge about how districts recruit candidates primarily because they were not currently seeking leadership positions. If more teachers are to explore leadership, then Human Resource Departments must understand their own organizational structures that hinder the flow of information throughout the district. Districts must look internally with a critical eye at the policies guiding recruitment practices to determine the effectiveness of those policies. A logical starting point in this analysis would be to determine how information about administrative vacancies flows through the organization and where communication breakdowns occur.

Beyond knowing that an administrative opening exists, districts need to increase the attractiveness of school administration as a career option. Research indicates that many do not pursue site leadership due to "inadequate training, insufficient salaries and a lack of general awareness of the positive aspects of school administration" (Young, Petersen, \& Short, 2001, p.8). This study reveals that innovative methods of recruitment should focus on the positive aspects of site leadership. Teachers such as Cat, a teacher with leadership potential who has experienced poor administrative models, must have an energetic, realistic, and balanced vision of the principal's role. Promoting the positive aspects of the site leadership role and casting a net to a broader base of possible future leaders will significantly enhance a district's recruitment practices. Further, districts must look beyond current teaching staff members with administrative credentials or those who have self-selected this career path to expand their applicant pool. Staff members who 
have demonstrated leadership potential but have not yet entered administrative training programs are an untapped candidate pool.

In spite of the minimal knowledge of recruitment policy and practices presented in the study, an administrator and a teacher expressed familiarity with a collaborative effort between the district and local universities to prepare and recruit candidates. This formalized structure --- school districts and university partners --- prepares teachers as future principals and is potentially a viable recruitment practice if coupled with more structured mentoring in the districts. Whitaker (2006) in "Preparing Future Principals," offers advice on how to prepare site administrators to meet future needs, describing the elements necessary to establish a successful university-district partnership. This partnership provides both instruction and mentoring of real life leadership experiences and cultivates leaders from within the organization to fill principal vacancies. The partnership allows a district to expand the pool of qualified leadership candidates that have a knowledge base about the structural and cultural workings of the district while at the same time reducing the stress and learning curve of a new administrator. Those who finish the program have sufficient training to juggle the multiple roles and responsibilities of a site leader.

District-university partnerships impart the current theories and expectations related to school leadership. But researchers expressed concern that teachers' experiences are embedded with traditional ideas, making it unlikely that those who move into site leadership positions will bring change or improvement to the role, even with formal training (Culbertson, et. al, 1969, Farguhar and Martin, 1971; Stout, 1973). Mario, a site administrator for more the 10 years, emphasized this point: "I think probably the 
biggest barrier is the lack of preparation for the role ... but the one thing I see missing is how you engender change at the very core level of people and their approach to things ... how do you change people right down to their values so that they work in a different way for a different intention?" District-university partnerships provide only a partial answer to Mario. When teachers experience new role models of leadership and develop collaborative, supportive relationships with leaders, then both positive change and recruitment of potential teacher-leaders is likely to improve.

\section{Cultural Influences: Mentoring}

While organizational structures are important to effective recruitment practices, cultural influences are a more significant factor in a person's decision to enter educational leadership. Networking systems play a critical role in teachers' experiences with, and exposure to, people who can support career advancement.

The culture of informal networks mentors teachers and provides districts with a greater pool of candidates to fill administrative vacancies. Teachers, consciously or unconsciously participate in a system of mentoring and support. They benefit by interacting with people who have the power to hire and/or who are in a position to recommend people for hire. Emeril, a site administrator for 9 years, benefited from this interaction when a university professor forwarded his name as a candidate for an administrative vacancy. Tyler, with 6 years of public and charter school leadership experience was guided by his mentor to move forward in assuming an administrative role.

Networks of formal and informal mentoring relationships serve two functions: 1) administrative mentors provide teachers with opportunities for experiences that build 
leadership capacity and ultimately a site leadership position, and 2) principals and other administrators encourage staff to apply for administrative vacancies or introduce staff to people in positions to hire someday.

Mentoring is a by-product of an open and functional workplace and the networks of human relations that evolve of time (Segiovanni, 1994). Informal mentoring relationships were evident within the organizational culture of all districts in this study. Effective principals naturally support teachers who display leadership potential; they both have a commitment to improve the education of children and the success of the school. Mentoring relationships originate naturally through personal connections and conscious efforts of teachers looking to contribute to the larger organization. Bobby, a relatively new teacher, actively sought experiences within the structure and culture of his school site that placed him in situations to be mentored. This was evidenced by the informal “apprenticeship" that he negotiated with his site administrators. Giada, a new site principal, shied away from mentoring teachers as she gained more confidence as a leader. A formal structure of mentoring would have trained Giada to immediately begin targeting, training, and recruiting future principals.

Districts that rely on informal networking systems as the primary method for recruiting new leaders, however, run the risk of a limited pool of qualified candidates to fill vacancies. Study participants often felt that personal allegiances based on race and gender, rather than actual qualification, acted as motivation for moving a person into a school leadership position. While study participants agreed that districts must actively work to diversify the leadership ranks, teachers and administrators raised concerns about a pendulum swing that places race as the foremost hiring criteria for new site leaders 
rather than the quality of diversity and qualifications. However accurate or false, recruitment and selection practices that are perceived to be based primarily on race and gender criteria - while arguably meeting the need for a diverse pool for applicants - may have unintended consequences. Those who do not feel a part of the "in group" will look to other districts for career advancement. (Marshall, 1992)

Study participants felt deeply that informal recruitment practices based solely on race- or gender-based networking systems foster a culture that advances people who are not skilled into leadership positions. Promotion based on race without the skills necessary for success potentially sets new leaders up for failure. Their authority is undermined because those they lead perceive that career advancement was based solely on race or gender rather than leadership skills and knowledge. Instead, mentors at the site level should contribute to a diverse candidate pool by providing opportunities for teacher-level leadership experience to a wide range of individuals with leadership potential including under-represented groups. One administrator shared his experience of being openly denied career advancement based on his race-white male; three participants stated that they had in fact benefited from a mentoring connection based on race.

There was consensus among study participants that informal recruitment practices foster the perception of this new "good old boys" network that benefits people of color to the exclusion of white males. There must be a system in place to guard against the perception of this new "exclusive minority" network when elevating people to leadership roles. If individual perceptions are accurate because the district structure and culture supports these "exclusive minority" networks, then perceptions of how vacancies are filled and by whom, will continue to undermine new administrators of color or women. 
Therefore, central to both the recruitment and success of new leaders is the perception of how a person ascends through the ranks.

The effect of mentoring relationships surfaced as the single most important factor in motivating a person to pursue a site leadership position. Moreover, the impact of mentors was significant for compelling a person to seek increased levels of responsibilities that will eventually lead to site leadership. Recent research indicates that districts do not suffer from a lack of applicants to fill administrative vacancies as previously anticipated. However, this pool is often void of highly qualified candidates (The Wallace Foundation, 2003). Formal mentoring programs support a district's recruitment efforts by systematically increasing that pool of qualified candidates for participation in the selection process that will fill anticipated vacancies. Additionally, when districts consciously work to build leaders from within their teaching ranks, those who move into site leadership have an intimate relationship with the organization and understand the cultural norms. This dramatically reduces the learning curve for a new administrator.

Implications for Leaders and Policy Makers

Interdependence of Culture and Structure

Difficulty arose in separating cultural and structural factors that influence an individual's decision to pursue site leadership. While specific factors where identified in each area, the impact of cultural and structural factors were often interdependent. For example, interviews reveal that informal mentoring relationships existed across districts and served as the driving force in propelling new and experienced teachers into 
administrative roles. A culture of mentoring was a critical element in a capacity building system. But at present successful mentoring is left to chance --- there are no formal mentoring structures to encourage more mentoring and to guide the successful mentor relationships into recruitment channels. Districts wanting to increase the pool of qualified candidates for administrative vacancies would benefit from structures within both the school and district that foster formal mentoring relationships and a culture of mentorship.

Formal structures within the district such as training programs for administrative mentors or a protocol that provides teachers with leadership opportunities go beyond recruitment through informal networking. Such structures would enhance recruitment practices by providing hiring personnel with more avenues of communication about mentored teachers with traits necessary to successfully lead a school site. Further, teachers take action when they are given the support and encouragement to develop their leadership abilities. Feeling appreciated and empowered, they choose to move within the organizational structure to take on positions of increased responsibility. This sense of belonging and purpose felt by Bobby and Paula moved them to participate in activities outside of their classroom in response to a mentoring relationship.

Formal mentoring relationships require an organizational structure that brings mentors and mentees together in a systematic way with the intent of developing a pool of qualified school leaders. The importance of this structure for developing leaders from within teaching ranks is supported in the literature. A thread running through each management movement influencing site leader behaviors is delegation. Delegating responsibilities allows opportunities for lead teachers. For districts to increase the pool of desirable candidates from within, emphasis must be placed on providing teachers with 
balanced experiences of educational leadership and managerial tasks. Responsibilities come with training, are appreciated, rewarded through evaluation, and are not isolated incidents without follow-up. Learning through delegated tasks prevents all those facets of school leadership from overwhelming a person who lacks the proper training and/or is not provided with support to balance the instructional and management aspects of a site administrator position.

Models of Leadership and Agency

While mentoring relationships between site or district leaders and teachers significantly influence teachers' exposure to leadership experiences, the models of leadership presented by site or district leaders also influences a person's decision to pursue school administration. The behavior of school leaders significantly shapes the perceptions of teachers about the complex role of a school administrator.

Most study respondents expressed a belief that, at times, felt they could do better than past and present models of site leadership, yet Cat, a talented teacher, was adamant in her refusal to consider a career path that includes an administrative position as an option. In Cat's experience, administrators emphasized managerial tasks, presenting a lopsided picture of the site administrator's role. It was a negative impression of endless management minutia. This mode of behavior runs the risk of discouraging teachers who have the potential to successfully lead a school, particularly when leadership models fail to match a person's internal image of the traits for effective leadership.

Walker (1990) identified twelve key skills of an exemplary principal: problem analysis, judgment, organizational ability, oral and written communication, decisiveness, leadership, sensitivity, stress tolerance, motivation, range of interests, and educational 
values. The skills recognized by Walker (1990) were also identified by study participants as skills and traits for successful leadership. Consistent with the research literature, administrators and teachers consistently identified effective communication skills and the ability to foster relationships as the essential traits of successful leaders. What is missing is an awareness of current administrators and teachers of the importance of communicating a common vision and focus, a trait highlighted in the literature (Clough, 1988; Mazzarella \& Grundy, 1989; Smith \& Andrews, 1989; Bass, 1990; Walker, 1990; Findley \& Findley, 1992; Fullan, 1992). Administrators were better able than teachers to articulate the traits necessary for effective leadership. Teachers' ideas of successful leaders and the traits they possess were based on an ideal and not on traits they personally embodied or experienced in someone they worked under.

Although negative models of site leadership were present across districts, mentors worked to provide a more nuanced impression and encourage the leadership potential in teachers who were discouraged by misconceptions of the role. Models of site leadership that present a multiplicity of common leadership responsibilities assist teachers in taking individual action and help them make an informed decision about the realities of an administrative position. Behaviors modeled by school leaders such as effective communication and the fostering of relationships impact a person's perception of who they are as potential leaders and whether they are willing to assume the growing burden of leading a school.

Site leadership models that demonstrate the multiple layers of responsibilities, and provide opportunities for teachers to take on leadership responsibilities, support teachers in making informed decisions about an appropriate career path that matches their skills 
and abilities. The discontent between an individual's perception of a strong leader and the models presented can steer a teacher-leader away from site leadership. Mentoring bridges the gap when potential administrative candidates experience a model of leadership that is inconsistent with their ideas of effective leadership traits. Successful leadership models supported by a culture of mentoring provide practical perspective for teachers in their decision-making process.

The role of a site administrator continues to evolve as states and districts figure out how to function under the No Child Left Behind Act (NCLB) which was signed into law January 8, 2002. While there is a belief among researchers that the growing demands of the job is a constraint in expanding the administrative candidate pool, site administrators interviewed for this study did not express dissatisfaction in the No Child Left Behind Act that makes them responsible for their site's instructional success. Teachers, in contrast to administrators who spoke positively of the accountability that comes with NCLB, worry about the multiple demands placed on site leaders, but did not feel this was a barrier to their decision to become administrators.

Most participants entered the teaching profession wanting to impact the lives of children on a large scale beyond the confines of the classroom setting. While influence from family and community provided a foundation for action, what solidified their desire to expand their level of influence through site leadership was the influence of the organizational culture on their evolving vision of the principal's role. The culture of a district, particularly mentorship and the leadership models presented to teachers, directly influenced a person's drive to assume an administrative position. This link between organizational culture and individual actions surfaced as a significant interdependent 
relationship; mentoring had a greater impact than formal organizational recruitment structures on a person's decision to assume a site leadership position.

\section{Recommendations for Further Study}

Data in this study suggests that teachers held a narrow image of the task and responsibilities associated with the principal's position. Further investigation into the actions and behaviors of site leaders that fosters a comprehensive understanding of the complex role of site leadership would aid effective recruitment practices for districts. By understanding the factors that influence teachers' perceptions of the task and duties associated with site leadership, districts can more effectively train administrators and adjust recruitment descriptions presented to teachers with leadership potential. Further studies are also necessary to analyze behavior that fosters informal mentoring relationships and cultivates leadership potential in teachers. Such studies will inform districts in the development of formal, more structured, mentoring programs.

\section{Conclusion}

Researchers estimate that the nation is experiencing a leadership crisis in the educational systems. Many current principals are of retirement age, and filling vacancies with qualified candidates prepared to handle the demanding role and responsibilities for student success is critical (Hertling, 1999; Levely, 1999; McCreight, 2001; Peterson \& Kelley, 2001; Gates, 2003; The Wallace Foundation, 2003). One solution was suggested by Marshall (1992) who found that informal recruitment methods-“"conversations, asides, gossip" and phone calls--have the greatest impact on identifying potential site 
leaders. Three key findings derived from this study contribute to this body of knowledge, leading to suggestions for innovative recruitment methods for a larger - and more diverse - pool of qualified school leadership candidates. These findings were: (1) informal mentoring is the most influential factor in guiding talented teachers into leadership. Districts should build on current informal recruitment methods by developing a formal structure of mentoring as a method for recruitment. (2) Perceptions that insufficiently-trained women and people of color are getting leadership jobs solely because of race or gender are detrimental to both leaders and recruitment. These perceptions undermine the authority of those leaders and prevent talentented individuals from applying for positions. Districts should implement a recruitment system that guards against a perception of a new "exclusive minority" network when elevating women and people of color to leadership roles. (3) Site leaders and teachers identified a set of traits that guide their own decision-making processes about movement into leadership.

Districts should utilize the skills individuals believe are necessary for effective leadership to identify potential leaders, better train positive models of successful leadership, and to portray the principal's job as a positive and rewarding position. While this study reveals that the prime motivation for pursuit of leadership occurs through mentoring, also important is personal ambition, family and community and role models. Hindering assent into leadership are poor role models or rotating leadership, poor recruitment communication, and poor training or transitional support for new principals, particularly when they are women or people of color. These findings - factors that motivate and discourage potential leaders-will support districts in the design and implementation of effective recruitment practice. 


\section{Limitations of the Study}

Having made these conclusions, limitations exist with the findings of this study. While study participants rest within three separate districts, the number of completed surveys from which to pull interview participants was limited. Additionally, the selection of teachers to participate in surveys and interviews depended on recommendations from site administrators and returned surveys from recommended teachers. A more positive aspect of a self critique is that three districts from which study participants were selected are similar in size but diverse in population, thus providing varied perspectives on the factors that contribute to one's decision to seek a site leadership position. 


\section{References}

Anderson, M. E. (1991). Principals: How To Train, Recruit, Select, Induct and Evaluate Leaders For America's Schools. University of Oregon: Eric Clearing House on Educational Management.

Bailey, J. F. (1992). The New Principal's Seven Commandments. Principal, 72(1), 13-14.

Baron, M. A. (1991). An analysis of public school superintendents' perceptions regarding the recruitment and selection of principals. (Doctoral Dissertation, University of Alabama, 1991).

Barth, R. S. (1980). How to Ensure an Effective Principalship. Principal, 59(3), 10-20.

Bass B. M. (1990). Bass \& Stogdill's handbook of leadership: Theory, research, \& managerial applications. New York: The Free Press.

Bass, B. M. (1985). Leadership and performance beyond expectations. New York: The Free Press.

Bogdan, R. and Biklen, S. (1992). Qualitative research for education (2 ${ }^{\text {nd }}$ Ed.). Boston: Allyn and Bacon.

Buell, N. A. (1992). Building a shared vision: The Principal's Leadership Challenge. NASSP Bulletin, 76(542), 88-92.

Calabrese, R. L. (2002). The Leadership Assignment: Creating change. Boston: Allyn and Bacon.

Callahan, R. E. (1962). Education and the Cult of Efficiency. Chicago: University of Chicago Press.

Clough, D. B. (1988). Trends in Elementary School Administration. Southwest Regional Workshop of the Arkansas Association of Elementary Principals, (ERIC Document Reproductive Services No. ED 324 755).

Coleman, J. S., Campbell, E. Q., Hobson, C. J., McFarland, J., Mood, A. M., Weinfeld, F. D., \& York, R. L. (1966). Equality of Educational Opportunity. Washington, D.C.: U.S. Government Printing Office.

Colon, R. J. (1994). Rethinking and Retooling for the $21^{\text {st }}$ Century: A Must for Administrators. NASSP Bulletin, October, 84-88.

Cuban, L. (2001). Leadership for Student Learning: Urban School Leadership --Different in Kind and Degree. Washington D. C. Institute for Educational Leadership. 
Culbertson, J., Green, T., \& Nelson, B. (1969). Preparing Educational Leaders for the Seventies. Columbus $\mathrm{OH}$ : University Council for Educational Administration.

David, T. (2000). Programs in practice: Teacher mentoring - benefits all around. Kappa Delta Pi Record, 36(3), 134-136.

Deal, T. E. (1987). Effective School Principals: Counselors, Engineers, Pawnbrokers, Poets . . . or Instructional Leadership? In Instructional Leadership: Concepts, Issues, and Controversies. William Greenfield (editor), (pp. 230-248). Boston: Allyn and Bacon.

DeMers, A. (2002). Solutions and Strategies for IT Recruitment and Retention: A Manager's Guide. Public Personnel Management, Spring, 21(1), p27-41.

Department of Labor (2006). Retrieved March 9, 2007, from http://www.bls.gov/oco/ocos007.htm\#outlook

DuFour, R., \& Eaker, R. (1998). Professional Learning Communities at Work: Best Practices for Enhancing Student Achievement. Bloomington, IN: National Educational Service.

Educational Leadership Development Academy: University of San Diego. Retrieved March, 9, 2007, from http://www.sandiego.edu/academics/soles/acadprog/elda/.

Elder, G. H. (1998). The life course as developmental theory. Child Development, 69, 1: $1-12$.

Elmore, R. F. \& Fuhrman, S. (2001). Holding Schools Accountable: Is It Working? Phi Delta Kappan, 83(1), 67-72.

ERS, NAESP, \& NASSP (Educational Research Service, National Association of Elementary School Principals, \& National Association of Secondary School Principals). (2000). The Principal, Keystone of A High-Achieving School: Attracting and Keeping the Leadership We Need. Arlington, VA: Educational Research Service.

Farguhar, R. \& Martin, M. W. (1971). New Developments in the Preparation of Educational Leaders. Phi Delta Kappan, 54(September), 25-29.

Fenwick, L. \& Pierce, M. (2001). The Principal Shortage: Crisis or Opportunity? Principal, 80(4), 24-32.

Findley, D \& Findley, B. (1992). Effective schools: The Role of the Principal. Contemporary Education, 63(2), 102-104. 
Fliegner, L.R. (1987). "Action interviews" Show You Who Can Cut The Mustard. Executive Educator, 9(4), 17-18

Frase, L. E. \& Melton R. G. (1992). Manager or Participatory Leaders? What Does It Take? NASSP Bulletin, 76(540), 17-24.

Fullan, M. G. (1992). Visions that blind. Educational Leadership, 49(5), 19-20.

Gardner, J. W. (1980). On Leadership. New York: The Free Press.

Gates, S. M., Ringel, J. S., Santibanez, L. Ross, K. E. \& Chung, C. H. (2003). Who Is Leading Our School? An Overview of School Administrators and Their Careers. Prepared for the Wallace-Readers' Digest Funds. Pittsburgh: RAND.

George, P. S. and Grebing, W. (1992). Seven Essential Skills of Middle Level Leadership. Schools In The Middle, 1(4), 3-11.

Getzels, J. W. \& Guba, E. G. (1957). Social Behavior and The Administrative Process. School Review, 65, 423-441.

Glense, C. (1999). Becoming Qualitative Researchers: An Introduction (2 ${ }^{\text {nd }}$ Ed.). New York: Addison Wesley Longman.

Goodlad, J. I. (1984). A Place Called School: Prospects for the Future. New York: McGraw Hill.

Grennfield, W. (1987). Instructional leadership: Concepts, issues, and controversies. Massachusetts: Allyn and Bacon, Inc.

Doud, J. L. (1989). The K-8 Principal in 1988: A Ten-Year Study. Alexandria, VA: National Association of Elementary School Principals.

Herse, P., \& Blanchard, K. (1982). Management of Organizational Behavior: Utilizing Human Resources (4th Ed.). Englewood Cliffs, NJ: Prentice Hall.

Hertling, E. (1999). Conducting a Principal Search. University of Oregon: Eric Clearing House on Educational Management.

Hill, C. W. L. \& Jones, G. R. (2001). Strategic Management 5th Ed, Houghton Mifflin, MeansBusiness, Inc.

Holloway, J. (2001). The benefits of mentoring. Educational Leadership, 58(8), 85-86. 
Jackson, B (2001). Exceptional and Innovative Programs in Educational Leadership. Paper Commissioned for the first meeting of the National Commission of the Advancement of Education Leadership Preparation. "Ensuring Universities' Capacity to Prepare Learning Focused Leadership" Racine, Wisconsin, September 19-21, 2001.

Kimbrough, R. B. \& Burkett, C. W. (1990). The Principalship: Concepts and practices. New Jersey: Prentice Hall.

Kowalski, T. J., Reitzug, U. C., McDaniel, P. \& Otto, D. (1992). Perceptions of Desired Skills for Effective Principals. Journal of School Leadership, 2(3), 299-309.

Leithwood, K. (2001). School Leadership and Educational Accountability: Toward a Distributed Perspective. In T. J. Kowalski \& G. Perreault (Eds.), 21st century challenges for school administrators, (pp. 11-25). Lanham, MD: Scarecrow Press.

Leithwood, K. A. (1992). The Move Toward Transformational Leadership. Educational Leadership, 49(5), 8-12.

Levely, S. (1999). Developing Leaders From Within. Thrust for Educational Leadership, 29(1), 12-13.

Lyman, L. R. (1988). The Principal: Responsive Leadership in Times of Change. School Administrators of Kansas. (ERIC Document Reproductive Services No. ED 293 201).

Naisbitt, J. (1984). Megatrends. New York: Warner Books.

Marlowe, J. (1992). Six Easy Lessons. Executive Educator, 14(10), 28-30.

Marshall, C. (1992). The Assistant Principal: Leadership Choices and Challenges. Newbury Park, California: Corwin Press, Inc.

Maxcy, S. J. (1981). Levels of Administrator Behavior: Practice, Policy, Philosophy, Kappa Delta Pi, 18(1), 14-17.

Mazzarella, J. A. \& Grundy, T. (1989). Portrait of a Leader. In S.C. Smith and P.K. Piele (eds.), School leadership: Handbook for excellence, (pp. 9-27). Eugene, Oregon: ERIC Clearinghouse on Educational Management.

McCreight, C. (2001). Solutions to Securing Qualified Principals. University of Oregon: Eric Clearing House on Educational Management.

Milstein, M. (1999). Reflections on "The Evolution of Educational Leadership Programs." Educational Administration Quarterly, 35(4), 537-545. 
Mitchell, T. (1982). People in Organizations, 2nd ed. New York: McGraw/Hill Book Company.

Murphy, J. (1990a). Preparing School Administrators for the Twenty-First Century: The Reform Agenda. In B. Mitchell \& L. L. Cunningham (Eds.), Educational leadership and changing contexts of families, communitities and schools, (pp. 232-251). Chicago: University of Chicago Press.

Murphy, J. \& Hallinger, P. (1992). The Principalship in An Era Of Transformation. Journal of Educational Administration, 30(2), 77-88.

National Association of Elementary School Principals (1990). Principals for $21^{\text {st }}$ Century Schools. Arlington, VA: Educational Research Service.

National Commission on Excellence in Education. (1983). A Nation At Risk: The Imperative For Educational Reform. Washington, D. C.: U. S. Government Printing Office.

New Leaders for New Schools. Retrieved March 9, 2007, from http://www.nlns.org/.

New Schools Venture Funds. Retrieved March 9, 2007, from http://www.newschools.org/.

Nickerson, N. (1982). The Principalship Revisited...Again. NASSP Bulletin, 436(May), 44-50.

Office of Research - Education Consumer Guide. Retrieved March 19, 2007, from http://www.ed.gov/pubs/OR/ConsumerGuides/mentor.html.

O'Laughlin, J. (January/February 2001). Recruitment: a Comprehensive Approach. Leadership, 30(3), 14-16.

Owen, R. G. (1987). Organizational Behavior in Education. Englewood Cliffs, NJ: Prentice Hall.

Parks, D. \& Barrett, T. (1994). Principals as Leaders of Leaders. Principal, 74(2). 11-12.

Peppers, L. \& Ryan, J. (1986). Discrepancies Between Actual and Aspired Self: A Comparison of Leaders and Nonleaders. Group \& Organization Management: Sage Publications, 11(3) 220-228.

Peterson, K. D. (1987). Administrative Control and Instructional Leadership. In Instructional leadership: Concepts, issues, and controversies. William Greenfield (editor), (pp. 139-154). Boston: Allyn and Bacon. 
Peterson, K. \& Kelley, C. (2001). Transforming School Leadership. Leadership, 30(3), 811.

Pharis, W. L. \& Zakariya, S. B. (1979). The Elementary School Principalship in 1978: A Research Study. Arlington, Virgina: National Association of Elementary School Principals, 1990. (ERIC Document Reproductive Services No. ED 320 223).

Principals for 21st Century Schools. Virginia: National Association of Elementary School Principals, 1990.

Rallis, S. F. \& Highsmith, M. C. (1986). The Myth of the "Great Principal": Questions of School Management and Instructional Leadership. Phi Delta Kappa, 68(4), 300304.

Reed, R. J. (1989). The Selection of Elementary and Secondary School Principals: Process and Promise. (ERIC Document Reproductive Service No. ED 316 913).

Richardson, S. C. (1987). The Principal: Gatekeeper of Change. (ERIC Document Reproductive Services No. ED 297 472).

Rodda, C. (2000). Searching for Success in Teacher Recruitment. Thrust for Educational Leadership, 29(3), 8.

Roethlishberger, F. T. \& Dickson, W. J. (1939). Management and The Worker. Cambridge, MA: Harvard University Press.

Senge, P. M., Cambron-McCabe, N., Lucas, T., Smith, B., Dutton, J., \& Kleiner, A. (2000). Schools That Learn: A Fifth Discipline Fieldbook for Educators, Parents, and Everyone Who Cares About Education. New York: Currency Doubleday.

Sergiovanni, T. J. (1994). Building Communities in Schools. San Francisco: Jossey-Bass.

Sergiovanni, T.J. (2001). The Principalship: A Reflective Practice Perspective (4th Ed.). Boston: Allyn and Bacon.

Smith, S. C. \& Piele, P. K. (1989). School Leadership: Handbook for Excellence. Portland, Oregon: ERIC Clearinghouse on Educational Management.

Smith, W. F. \& Andrews, R. L. (1989). Instructional Leadership: How Principals Make A Difference. Virgina: American Association for Curriculum Development.

Snyder, W. R. \& Drummond, W. H. (1988). Florida Identifies Competencies for Principals, Urges Their Development. NASSP Bulletin, 72(512), 48-58.

Spain, C. L., Drummond, H. D. \& Goodland, J. I. (1956). Educational Leadership and The Elementary School Principal. New York: Rinehart \& Company. 
Spradley, J. P. (1979). The Ehtnographci Interview. Orlando: Harcourt Brace Jovanovich, Inc.

Srivastva, S. (1986). Executive Power. London: Jossey-Bass Publishers.

Steller, A. W. (1984). Chart A New Course for Selecting New Principals. Updating School Board Policies, 15(5), 1-4.

Stout, R. T. (1973). New Approaches to Recruitment and Selection of Educational Administrators. Columbus, $\mathrm{OH}$ : University Council for Educational Administration.

Sweeney, J. (1982). Research on Effective School Leadership. Educational Leadership, $39,346-352$.

Taylor, S. J. \& Bogdan, R. (1984). Introduction to Qualitative Research Methods: The Search for Meaning. $2^{\text {nd }}$ ed. New York: John Wiley, 1-2.

The Wallace Foundation. (2003). Beyond the Pipeline: Getting The Principals We Need, Where They Are Needed Most (A Policy Brief by The Wallace Foundation). New York: Lee D. Mitgang.

Thomson, S. D. (1992). School Leadership: A Blueprint for Change. Newbury Park, California: SAGE Publishing.

Ubben, G. C. \& Hughes, L. W. (1987). The Principal: Creative Leadership for Effective Schools. Boston: Allyn and Bacon, Inc.

Walker, J. E. (1990). The Skills of Exemplary Principals. NASSP Bulletin, 74(524), 4855.

Walker, L. (1995). The Principal Selection Process In Washington State Pubic Schools: A Comparison Of Superintendents' And Principals' Personal Beliefs and Implementation Perceptions. (Doctoral Dissertation, Gonzaga University, 1990). Dissertation Abstracts International, 56, 07A.

Weiss, R. S. (1992). The Elementary School Principalship: A Historical Evolution. (Doctoral Dissertation: University of Massachusetts)..

Wendel, F. C. \& Breed, R. D. (1988). Improving the Selection of Principals" An Analysis of Approaches. NASSP Bulletin, 72(508), 35-38.

Whitaker, K. (May 2001). Where are the Principal Candidates? Perceptions of Superintendents. NASSP Bulletin, 85(635), 82-92. 
Whitaker, K. (2006). Preparing Future Principals. Principal Leadership: High School Edition, November, 38-42.

Wood, R. \& Payne, T. (1998). Competency Based Recruitment and Selection: A Practical Guide. New York: John Wiley \& Sons, Inc.

Young, M. D., Petersen, G. J., \& Short, P. M. (2001, September). The Complexity of Substantive Reform: A Call for Interdependence Among Key Stakeholders. Commissioned Paper presented at the National Commission for the Advancement of Educational Leadership Preparation Conference, Racine, WI.

Yukl, G. A. (1989). Leadership in Organizations. New Jersey: Prentice Hall. 
Appendix A

Survey - Administrator 
Survey - Administrators

\section{$\underline{\text { 1. Introduction }}$}

Thank you in advance for taking time from your day to complete this survey.

SURVEY RESPONSES ARE ANONYMOUS. However, your willingness to participate further in this research study is greatly appreciated. If you would like to be considered for participation in a one hour interview you will have the opportunity at the end of this survey to provide your name and email address.

After completing the survey, you will be prevented from entering additional responses. However, if you have to leave the survey before it is complete you may return and will be taken to the point that you left off.

This survey is being conducted to ascertain three types of information.

1. To gain insight into the factors that contribute to a person's decision to pursue (or not pursue) an administrative position.

2. To build a framework of characteristics that current principals use to identify a teacher who has site leadership potential.

3. To gather names from principals of teachers who have site leadership potential so that they may be included in this research.

\section{Background Information}

Gender
- Female
- Male

Age

- $22-25$

- 26-30

- $31-35$

- $36-40$

- $41-45$

- 46-50

- $51-55$

○ 56 \& Over 
How do you identify yourself in terms of race/ethnicity?

- Hispanic

- Black or African American

- Native Hawaiian or Other Pacific Islander

- American Indian or Alaska Native

- Asian

- White

Other (please specify)

\section{Training}

How long have you worked in the educational field?

Total number of year's

What is the highest graduate degree, if any have you earned?

- Specialist degree

- Master's degree (MA, MS)

- Master's of Education (M. Ed.)

- Doctorate (Ed. D. or Ph. D.)

- No Degree

$\circ$ Other (please specify)

Do you hold an administrative credential?

$\circ$ Yes

- No

Where did you complete your administrative credential program?

What year did you complete your initial administrative training program

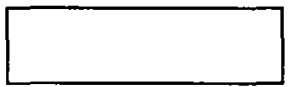

What certification for school administration do you currently hold?

- Probationary certification

- Permanent or professional clear credential

- I am currently working on a certification for school administration

- Other administrative certification (please specify) 


\section{Current History}

What is your current job title?

What school leadership positions do you hold or have you held in the past? (Mark all that apply)

- Member of a Shared-Decision Making team or Committee

- Resource Teacher

- School Club Sponsor

- Person in Charge of School-Wide Event (i.e. awards assembly, science fair)

- Athletic Coach or Director

- Peer Coach

- Department Chair

- Grade Level or Subject Area Teacher Leader

How many years total have you worked in each area?

\begin{tabular}{|l|l|l|l|l|l|l|l|l|l|l|l|l|}
\hline & 0 & $<1$ & 1 & 2 & 3 & 4 & 5 & 6 & 7 & 8 & 9 & $>9$ \\
\hline $\begin{array}{l}\text { Classroom } \\
\text { Teacher }\end{array}$ & & & & & & & & & & & & \\
\hline $\begin{array}{l}\text { Classroom } \\
\text { Teacher/Resource } \\
\text { Teacher }\end{array}$ & & & & & & & & & & & & \\
\hline $\begin{array}{l}\text { Resource Teacher } \\
\text { - School Site }\end{array}$ & & & & & & & & & & & & \\
\hline $\begin{array}{l}\text { Resource Teacher } \\
\text { - District Level }\end{array}$ & & & & & & & & & & & & \\
\hline $\begin{array}{l}\text { Peer Coach/Staff } \\
\text { Developer }\end{array}$ & & & & & & & & & & & & \\
\hline $\begin{array}{l}\text { Content } \\
\text { Administrator }\end{array}$ & & & & & & & & & & & & \\
\hline Vice Principal & & & & & & & & & & & & \\
\hline Principal & & & & & & & & & & & & \\
\hline
\end{tabular}

Which best describes your school district population?
o K-6
○ $7-12$
○ $\mathrm{K}-12$ 
Which best describes your school site population?

○ K-5

$\circ \mathrm{K}-8$

○ $6-8$

- $9-12$

- Other (please specify)

\section{School Leadership}

When obtaining your administrative credential did you intend to pursue a vice principal/principal position?

$\circ$ Yes

- No

If you answered "No" to the previous questions, what changed your decision?

Describe what you believe to be the most important skills for a school site leader.

Describe those things that you perceive to be barriers preventing people from pursuing school leadership positions. 
What qualities are necessary to be a successful principal?

What characteristics do you look for in a certificated staff member who you believe would be an excellent candidate for a site leadership position?

\section{Recruitment Practices}

Do you feel that school leaders in your district are diverse in gender and race/ethnicity?

- Yes

- No

Do you believe your district actively recruits women and minorities for school leadership positions?

- Yes

- No

In what ways do you feel that the district recruits a diverse group of school leaders? 


\section{Research Participants}

This section serves to expand the pool of research participants to include certificated staff.

Our willingness to provide names of staff members who have the potential to be excellent site leaders is greatly appreciated and your anonymity in recommending each for participation is this study is assured.

Please list the names and email addresses of teachers whom you believe possess the qualities for successful school leadership.

\section{Interview Portions of Study}

Thank you again for your time in completing this survey.

As a small token of appreciation for your willingness to participate in the interview portion of this study you will receive a $\$ 5.00$ certificate to Starbucks or Barnes and Noble.

Interviews will be conducted to expand on the information obtained in this survey. Survey responses remain anonymous. However, your willingness to participate further in this research study is greatly appreciated. If you would like to be considered for participation in a one hour follow-up interview please provide your name and email address below.

I am interested in participating in the interview portion of this study

- Yes

- No 


\section{Further Study Participation}

The first 15 people to respond as volunteers for the interview portion of this study will have their names placed into a drawing for an Outback Steakhouse certificate (\$30 value).

Again thank you for taking the time to support this study through your participation.

Please provide your name, email address and school location if you are interested in participating in a follow-up interview.

Name

School Location

Please send me the following gift certificate for my willingness to participate in the interview portion of this study.

- Starbucks

- Barnes and Noble

\section{End}

Thank you for your participation. 
Appendix B

Survey - Teacher 
Survey - Teacher

\section{Introduction}

Thank you in advance for taking time from your day to complete this survey.

SURVEY RESPONSES ARE ANONYMOUS. However, your willingness to participate further in this research study is greatly appreciated. If you would like to be considered for participation in a one hour interview you will have the opportunity at the end of this survey to provide your name and email address.

After completing the survey, you will be prevented from entering additional responses. However, if you have to leave the survey before it is complete you may return and will be taken to the point that you left off.

This survey is being conducted to ascertain two types of information.

1. To gain insight into the factors that contribute to a person's decision to pursue (or not pursue) an administrative position.

2. To gain insight into teaches' perceptions of the role and expectations of today's principal position.

\section{Background Information}

Gender

○ Female

○ Male

Age

○ $22-25$

- $26-30$

○ $31-35$

○ $36-40$

- $41-45$

- 46-50

$51-55$

- 56 \& Over 
How do you identify yourself in terms of race/ethnicity?
- Hispanic
- Black or African American
- Native Hawaiian or Other Pacific Islander
- American Indian or Alaska Native
- Asian
- White
O Other (please specify)

\section{Training}

How long have you worked in the educational field?

Total number of year's

What is the highest graduate degree, if any have you earned?

- Specialist degree

- Master's degree (MA, MS)

- Master's of Education (M. Ed.)

- Doctorate (Ed. D. or Ph. D.)

- No Degree

O Other (please specify)

Do you hold an administrative credential?
- Yes (go to \# 4)
- No (go to \# 5)

\section{Administrative Credential Information}

Where did you complete your administrative credential program?

What year did you complete your initial administrative training program

What certification for school administration do you currently hold?

- Probationary certification

- Permanent or professional clear credential

- I am currently working on a certification for school administration

- Other administrative certification (please specify) 


\section{Current Status}

What is your current job title?

What school leadership positions do you hold or have you held in the past? (Mark all that apply)

- Member of a Shared-Decision Making team or Committee

- Resource Teacher

- School Club Sponsor

- Person in Charge of School-Wide Event (i.e. awards assembly, science fair)

- Athletic Coach or Director

- Peer Coach

- Department Chair

- Grade Level or Subject Area Teacher Leader

How many years total have you worked in each area?

\begin{tabular}{|l|l|l|l|l|l|l|l|l|l|l|l|l|}
\hline & 0 & $<1$ & 1 & 2 & 3 & 4 & 5 & 6 & 7 & 8 & 9 & $>9$ \\
\hline $\begin{array}{l}\text { Member of a shared- } \\
\text { decision making team } \\
\text { or committee }\end{array}$ & & & & & & & & & & & & \\
\hline $\begin{array}{l}\text { Athletic coach or } \\
\text { director }\end{array}$ & & & & & & & & & & & & \\
\hline $\begin{array}{l}\text { Person in charge of a } \\
\text { school-wide event }\end{array}$ & & & & & & & & & & & & \\
\hline $\begin{array}{l}\text { Resource Teacher - } \\
\text { District Level }\end{array}$ & & & & & & & & & & & & \\
\hline $\begin{array}{l}\text { Grade level or subject } \\
\text { area team leader }\end{array}$ & & & & & & & & & & & & \\
\hline Peer Coach & & & & & & & & & & & & \\
\hline Department Chair & & & & & & & & & & & & \\
\hline School club sponsor & & & & & & & & & & & & \\
\hline
\end{tabular}

Which best describes your school district population?
○ K-6
○ $7-12$
○ $\mathrm{K}-12$ 
Which best describes your school site population?

○ K-5

○ $\mathrm{K}-8$

○ 6-8

$\circ \quad 9-12$

- Other (please specify)

\section{School Leadership}

If you do not currently hold an administrative services credential, have you ever considered obtaining one?

- Yes (go to \# 8)

- No (go to \# 7)

\section{Contributing Factors to Decisions}

What factors contribute to your decision not to pursue an administrative services credential?

Do you foresee at time that you may pursue an administrative services credential?

- Yes

$\circ$ No

\section{Future}

Do you intend to pursue a site administrator job now or in the future?

- Yes (go to \#9)

○ No (go to \#10)

\section{Pursue a Leadership Position}

Please explain what factors influence your decision to pursue a school site leadership position in the future. 


\section{Not Pursue a Leadership Position}

Please explain what factors influence your decision not to pursue a school site leadership position in the future.

\section{Recruitment (Women/Minority)}

Do you feel that school leaders in your district are diverse in gender and race/ethnicity?

O Yes

$\circ$ No

Do you believe your district actively recruits women and minorities for school leadership positions?

- Yes

- No

In what ways do you feel that the district recruits a diverse group of school leaders?

\section{School Site Leadership}

Describe what you believe to be the most important skills and characteristics for a school site leader.

Describe those things that you perceive to be barriers preventing people from pursuing school leadership positions. 
Describe what you believe to be the forces that motive a person to pursue an administrative position.

What qualities do you believe make a successful principal?

\section{Interview Portions of Study}

Thank you again for your time in completing this survey.

As a small token of appreciation for your willingness to participate in the interview portion of this study you will receive a $\$ 5.00$ certificate to Starbucks or Barnes and Noble.

Interviews will be conducted to expand on the information obtained in this survey. Survey responses remain anonymous. However, your willingness to participate further in this research study is greatly appreciated. If you would like to be considered for participation in a one hour follow-up interview please provide your name and email address below.

Interviews will be approximately one hour in length.

I am interested in participating in the interview portion of this study
o Yes
- No 


\section{Further Participation}

The first 15 people to respond as volunteers for the interview portion of this study will have their names placed into a drawing for an Outback Steakhouse certificate (\$30 value).

Again thank you for taking the time to support this study through your participation.

Please provide your name, email address and school location if you are interested in participating in a follow-up interview.

Name/Email

School Location

Please send me the following gift certificate for my willingness to participate in the interview portion of this study.

- Starbucks

- Barnes and Noble

\section{End}

Thank you for your participation. 


\section{Appendix C}

Introduction Email - Administrator 
Dear Site Administrator,

I am a doctoral candidate in Educational Leadership at the University of San Diego and I am seeking study participants for my dissertation research.

This study intends to investigate the factors that influence a person's decision whether or not to pursue a school administrator position. Discovering reasons that discourage a person from seeking career advancement into principal positions will indicate whether a need exists to address recruitment policies and procedures in order to attract a larger pool of qualified applicants for school administrator positions.

Your willingness to respond to a short on-line survey is greatly appreciated. The survey will take approximately 10-15 minutes. Participation in this study is strictly voluntary. You may withdrawal from participation at any time without risk of penalty. I am also seeking a handful of people to participate in a one (1) hour interview to gather further information.

There are no foreseeable risks or discomforts for your participation in the interview portion of this study. Additionally, you will be provided with a copy of the transcript for review after the interview session.

All study records are confidential. However the aggregate results may be made public. Access to your initial survey responses are password protected. Further, all study related computer files are password protected. All other documents are kept in a locked file cabinet. The researcher is in sole possession of the passwords and file cabinet keys. All study records will be retained for a minimum of five year before being destroyed.

As a small token of appreciation for your willingness to participate in the interview portion of this study you will receive a $\$ 5.00$ gift card to Starbuck or Barnes and Nobles (your choice - selection at end of survey)

Additionally, the first 15 people to respond as volunteers for the interview portion of this study will have their names placed into a drawing for an Outback Steakhouse certificate (\$30 dollar value).

Thank in advance for taking time from your day to complete this survey. Please contact me at ginger_lee_blackmon@yahoo.com if you have any questions about this study.

The survey can be found by clicking on the following link:

Respectfully, Ginger Lee Blackmon 
Appendix D

Introduction Email - Teacher 
Dear [Teacher Name],

I am a doctoral candidate in Educational Leadership at the University of San Diego. Your name has been given to me by a district administrator as someone who possesses school leadership potential. Additionally, it is believed that you would be an excellent candidate for participation in my dissertation research.

This study intends to investigate the factors that influence a person's decision whether or not to pursue a school administrator position. Discovering reasons that discourage a person from seeking career advancement into principal positions will indicate whether a need exists to address recruitment policies and procedures in order to attract a larger pool of qualified applicants for school administrator positions.

Your willingness to respond to a short on-line survey is greatly appreciated. The survey will take approximately $10-15$ minutes. Participation in this study is strictly voluntary. You may withdrawal from participation at any time without risk of penalty. I am also seeking a handful of people to participate in a one (1) hour interview to gather further information.

There are no foreseeable risks or discomforts for your participation in the interview portion of this study. Additionally, you will be provided with a copy of the transcript for review after the interview session.

All study records are confidential. However, the aggregate results may be made public. Access to your initial survey responses are password protected. Further, all study related computer files are password protected. All other documents are kept in a locked file cabinet. The researcher is in sole possession of the passwords and file cabinet keys. All study records will be retained for a minimum of five year before being destroyed.

As a small token of appreciation for your willingness to participate in the interview portion of this study you will receive a $\$ 5.00$ gift card to Starbuck or Barnes and Nobles (your choice - selection at end of survey)

Additionally, the first 15 people to respond as volunteers for the interview portion of this study will have their names placed into a drawing for an Outback Steakhouse certificate (\$30 dollar value).

Thank in advance for taking time from your day to complete this survey. Please contact me at ginger lee blackmon@yahoo.com if you have any questions about this study

The survey can be found by clicking on the following link:

Respectfully, Ginger Lee Blackmon 